\title{
Brave Spaces: Augmenting Interdisciplinary STEM Education by Using Quantitative Data Explorations to Engage Conversations on Equity and Social Justice
}

John R. Jungck

University of Delaware, jungck@udel.edu

Jon Manon

University of Delaware, jonmanon@udel.edu

Follow this and additional works at: https://digitalcommons.usf.edu/numeracy

Part of the International and Comparative Education Commons, Population Biology Commons, Race and Ethnicity Commons, and the Science and Mathematics Education Commons

\section{Recommended Citation}

Jungck, John R., and Jon Manon. "Brave Spaces: Augmenting Interdisciplinary STEM Education by Using Quantitative Data Explorations to Engage Conversations on Equity and Social Justice." Numeracy 12, Iss. 1 (2019): Article 4. DOI: https://doi.org/10.5038/1936-4660.12.1.4 


\title{
Brave Spaces: Augmenting Interdisciplinary STEM Education by Using Quantitative Data Explorations to Engage Conversations on Equity and Social Justice
}

\begin{abstract}
In workshops and courses involving in-service teachers, participating teachers can engage in problem posing and exploration of difficult issues when they are asked to quantitatively model alternative scenarios, statistically analyze complex data, and visualize these data in multiple formats. Subsequent to these activities, discussions of sensitive issues, some even considered taboo in classrooms, can open up "brave spaces" in these teachers' classrooms. Without coaching through elaborate facilitation strategies, the in-service teachers grappled openly with the nuances of such difficult issues and raised many alternatives involving quantitative reasoning as well as considering biological, cultural, economic, social, and political factors influencing social justice and civil rights decisions and policies. We have adapted this pedagogical approach from the literature on brave spaces with the important difference being that, instead of beginning with a discussion of difficulties in having such discussions, we wait for the participants to raise the issues themselves. Herein we report on two controversial examples dealing with population growth: China's one-child policy and the tremendous increase in the population of slaves during the pre-Civil War period in the US after legal importation of slaves was outlawed earlier in the century. In the first case, the teachers modeled multiple scenarios for reducing population growth and in the second case, they statistically analyzed the historical data.
\end{abstract}

\section{Keywords}

brave spaces, social justice, modeling, statistical analysis, visualization

\section{Creative Commons License}

(c) (i) (8)

This work is licensed under a Creative Commons Attribution-Noncommercial 4.0 License

\section{Cover Page Footnote}

John R. Jungck is Director of the Interdisciplinary Sciences Learning Center at the University of Delaware as well as a Professor of Biological Sciences and Mathematical Sciences. He founded the BioQUEST Curriculum Consortium (http://bioquest.org). He is a Fellow of AAAS, the recipient of the Bruce Alberts Award, and the former editor of several journals. He was a charter board member of the National Numeracy Network.

Dr. Jon Manon is a STEM educator who held appointments in the College of Education and the Department of Mathematical Sciences at the University of Delaware until his retirement in 2017. He was the Director of the Mathematics \& Science Education Resource Center for seven years and has served as co-PI on many grants promoting a problem-based approach to teaching and learning in $\mathrm{K}-12$ mathematics. Jon helped pioneer the use of classroom video to support a more reflective pedagogical practice and is currently co-PI on the DISCovery Delaware MSP-funded project.

Revised 2-13-2019 with a higher-resolution graphic in Figure 1, courtesy of an anonymous reader using figures from the same Census Bureau site. 


\section{Introduction: Creating Brave Spaces for STEM Learning}

Education for social justice is, we believe, an interdisciplinary project. Engaging students in problem-posing that involves the examination and analysis of data with modeling, visualization, statistical analysis, and, ultimately, ethical discussion allows educators to co-construct brave spaces for productive discourse on culturally sensitive, even potentially taboo, subjects.

We were inspired by the work of Robert Moses and C. E. Cobb (2001) to make and explore conjectures using mathematical evidence. The two professional development teaching experiences for high school teachers that we will describe in this paper, linked as instances of population "engineering," will address two problems: a global one and a national one. Both experiences look to the future and examine the past while incorporating multiple aspects of quantitative thinking (modeling, combinatorics, probability, statistics), and considering the utility of multidimensional visualizations. These two teaching experiences occurred in two different contexts: a professional development workshop with in-service high school teachers, and a graduate class with in-service high school teachers roleplaying as students. Our goal in each case was to collaborate with the teachers to develop the "tools they need to be agents of social change" and to foster "the tools and dispositions" for "active participation in democratic public life" (Gutstein et al. 1997, 711).

We were motivated to develop these two teaching experiences because exponential human population growth was an issue that was identified in the 1960s, but it is now clear that many poor assumptions were made at that time by biologists, economists, and mathematical modelers. To that point, Hans Rosling et al.'s (2018) recent book Factfulness, illustrates that the majority of scientists, news reporters, and other citizens are still misinformed about whether the world faces an imminent risk from continued growth of the human population. The authors argue forcefully for a critical engagement with actual data and an understanding of quantitative relationships among biological, cultural, demographic, political, and social variables. Similarly, in The Wizard and The Prophet, Charles C. Mann (2018) argues that we need to address the environmental issues surrounding population growth by moving beyond the dichotomy between a "techno" optimism and an "end-of-the-world" pessimism. As we developed these two experiences for teachers, we collected data from diverse sources, examined a variety of quantitative tools for modeling and visualizing demographic data and trends, and drew upon the science and mathematics education literature on the pedagogical importance of using controversy in the classroom, especially with regard to contexts that address issues of social justice. 
We have been influenced by a literature that identifies how to go from safe spaces to brave spaces in the classroom (Arao and Clemens 2013; Cook-Sather 2016; Perez-Putnam 2016; Reyes and Adams 2017), where "safe space implies that danger, risk, or harm will not come to one in that space-that the space as constructed precludes the possibility of those phenomena" (Cook-Sather 2016, 1). It may, in fact, be that the idea of the classroom as a safe space is largely a "chimera" and that although "most students anticipate that the classroom is not a space in which they should necessarily feel hurt, alienated, silenced, or misunderstood, ... the conventions which construct classroom space can and do contribute to these emotional responses" (Redmond 2010, 3). In particular, Arao and Clemens (2013) found that students tend to conflate the idea of safe spaces with the notion of comfortable discourse, and so they have begun "shifting from the concept of safety and emphasizing the concept of bravery instead, to help students understand - and rise to the challenges of genuine dialogue on diversity and social justice issues" (Arao and Clemens 2013, 136).

Therefore, we chose to structure our lessons on population growth by beginning with a look at data, introducing tools for modeling and data analysis, and then, letting ethical questions emerge naturally from participants as they wrestled with their growing understanding of the problems in context. We posit that a data-intensive exploration can ground such bravery in a shared experience and perhaps even blur the lines of "agent" vs. "target" group membership (that is, the lines between students who bring a privileged identity into the setting and students who do not) (Arao and Clemens 2013, 139) by creating a common identity of membership in a data-driven, civil dialogue. This requires, we believe, that the social justice questions emerge naturally from a shared experience of modeling and data analysis. Our strategy was based upon presenting various perspectives on the problem (e.g., setting the stage with our "four quotes" below), sharing a wealth of data and multiple resources for modeling that data, encouraging small-group investigations, and then, finally, calling for questions in an open-ended, collaborative discussion that publicly respects the reasoning of all participants.

Our development of these experiences was also informed by what seem to us to be a confluence of pedagogical imperatives for today's science, technology, engineering, and mathematics (STEM) classrooms. The first imperative is that powerful STEM learning can best occur in interdisciplinary contexts. The second imperative is that lessons should be framed and taught as problem-based explorations, in this instance, global population growth and the history of abuse of slaves in America (e.g.,Van Harpen and Presmeg 2013; Cai et al. 2015). The third is that both context and content matter (Harwell et al. 2012; Post et al. 2012; Honey et al. 2014). We believe that contexts for STEM lessons that involve elements of social justice are likely to be empowering for a wide range of students 
and perhaps most importantly for students typically under-served in U.S. K-12 STEM education given "the disparities in learning opportunities and outcomes in mathematics education based on race, class, culture, language, and gender" (National Council of Supervisors of Mathematics and TODOS 2016, 1).

Recently, the National Council of Supervisors of Mathematics (NCSM) and TODOS: Mathematics for All (the Spanish word "todos" translates as "all" or "everyone") issued a joint policy statement on teaching mathematics for social justice (NCSM and TODOS 2016). The rationale for doing so was articulated as follows:

The National Council of Supervisors of Mathematics (NCSM) and TODOS: Mathematics for ALL (TODOS) ratify social justice as a key priority in the access to, engagement with, and advancement in mathematics education for our country's youth. A social justice stance requires a systemic approach that includes fair and equitable teaching practices, high expectations for all students, access to rich, rigorous, and relevant mathematics [our emphasis], and strong family/community relationships to promote positive mathematics learning and achievement. (NCSM \& TODOS 2016, 1)

We believe that this stance should be extended to all STEM subjects and applies particularly well to interdisciplinary, problem-based learning where instruction is focused around real-world problems.

An emergent literature on teaching mathematics for social justice, (e.g., Frankenstein 2013; Tate 2013; NCSM and TODOS 2016; and Gutstein 2018) suggests that equitable instruction should take advantage of culturally relevant contexts and community funds of knowledge, often located quite directly in the students' immediate experiences. We also believe that students should be invited to participate in experiences about issues of national and global significance in order to position themselves as citizens of the wider world. For this reason, we took on the challenge of developing a series of problem-based experiences around the issue of population growth.

In this article, we approach difficult issues on population growth in two different professional development experiences for high school teachers. In the first, we look at the global population of the earth primarily through modelling alternatives to the historical case of China's one-child policy. Overpopulation of humans on the planet earth has been recognized as a major environmental problem and it is a sensitive issue. Consequently, it is almost never directly dealt with in public classrooms. Yet, we contend that: (1) population growth is an important environmental issue that impacts almost all other environmental problems, and (2) there are many misconceptions about what the best current expectation of population growth is and where we are headed. The editor of Arc Technica, Annalee Newitz (2013) considers it one of the fundamental debates of our time. 
In the second professional development experience for teachers, we look at the U.S. historical case of slave breeding through statistical analysis and visualization. Because race and the legacy of slavery is also a contentious issue, and because the history of underrepresented groups is often ignored in quantitative reasoning (Gutstein and Peterson 2013; Shetterly 2016), we chose to look at the data of actual populations over the period from the cessation of the importation of slaves in 1808 until 1864 at the end of the Civil War.

In both of these teaching experiences, we approached brave spaces by preceding discussion of these issues with mathematical modeling and statistical analysis. In sum, engaging controversy affords an opportunity for students to understand and to learn to engage in civil discourse, to see the importance of data and modeling, and to make evidence-based decisions on complex issues. This topic is one that affords an excellent opportunity for STEM-centric, problembased learning.

\section{Exploration One: Mathematics and Biology in a Public Policy Context}

The question of human population growth has figured prominently in the thinking and public pronouncements of both academicians and world leaders. Here is a sampling of important perspectives that set the stage for our first exploration with our cohort of high school teachers.

Chairman Mao: "The more people there are, the stronger we are." (Vanerklippe 2015)

Paul Ehrlich: "People should produce far fewer children or expect the worst." (Ehrlich 1968)

Julian Simon: "Population is the solution to resource scarcities and environmental problems, since people and markets innovate." (Simon 1989)

Hans Rosling et al.: "Don't Panic —The world might not be as bad as you might believe!" (Rosling et al. 2018)

\section{Enacting Our Teaching Experiences with High School Teachers}

We, the authors of this paper, have been funded for the past five years to develop and implement a unique program of professional development for teams of high school STEAM (science, technology, engineering, art, and mathematics) teachers. STEAM teams from a dozen high schools in our region have participated in DISCovery: The Discover Delaware Interdisciplinary STEAM Citizen Science Project. Participating teachers experienced interdisciplinary, problem-based learning in the University of Delaware's new Interdisciplinary Science \& 
Engineering (ISE) Laboratory during a two-day winter workshop, designed interdisciplinary lessons for use with high school students in the spring, and then conducted a week-long academy for secondary students in the ISE Lab in June. Based upon their assessments from the summer academy, they refined these lessons for use in their own classrooms in the subsequent fall term. Cycles of learn, design, implement, and refine were repeated during our five years of Mathematics and Science Partnership (MSP) project funding. ${ }^{1}$

Each year, as we designed the professional learning experiences for the twoday winter workshops, we searched for unifying themes and important contexts in which to set the interdisciplinary STEAM activities. In January 2017, we opted to present a multi-session workshop addressing the issue of population growth. We designed a case study involving the development of public policy to explore possibilities for engaging students in an interdisciplinary use of mathematics and science. We began the workshop by examining how a prominent population biologist, Paul Ehrlich, set off an international discussion based upon his controversial book, The Population Bomb (1968), and ultimately engendered the establishment of a grass root movement called "Zero Population Growth." We initiated this first teaching experience in our workshop by watching the first seven minutes of a "Retro Report" by The New York Times on the Ehrlich era and followed up with a question for small groups probing Ehrlich's assumptions about global population growth. Small groups posted their assumptions on the classroom walls and addressed their evidentiary support for each assumption. As a first engagement with these potentially controversial, even explosive, concepts, groups aired and shared a range of views, but since we were not pushing for judgments at this point, the temperature of these discussions remained relatively cool.

One historical consequence of views such as Ehrlich's about population growth, as captured in his introductory quote, was China's development of its controversial one-child policy (Feng et al. 2012). We asked participants to consider how loosening China's one-child policy would affect its ability to stabilize or reduce its population size. We asked them to do this in four policy subgroups: (1) maintain the one-child policy (the "one-and-done" policy), (2) allow two children per family, (3) allow three children per family, and (4) stop having children when a male child is born (a "son-and-done" strategy).

After groups reported out on their initial thinking about the potential impact of the policy they were analyzing, we provided additional data representations in order to make possible a more nuanced analysis. We asked our teachers to decide which of the Population Pyramids in Figure 1 might best describe the population

1 The MSP project was funded by the U.S. Department of Education through state-awarded competitive grants. The authors secured two successive grants, the first from 2013 to 2016, and the second from 2016 to 2018. 
of China and to explain why. Country names were hidden initially in this challenge and our participants were encouraged to first consider macrodifferences among the pyramids, visible even in this reduced reproduction, rather than the actual data encrypted in each.



A

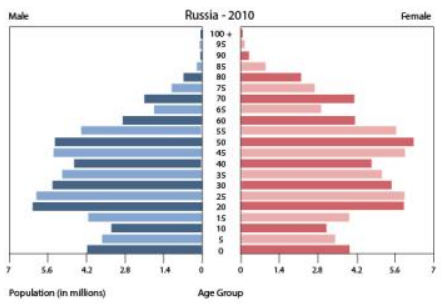

D

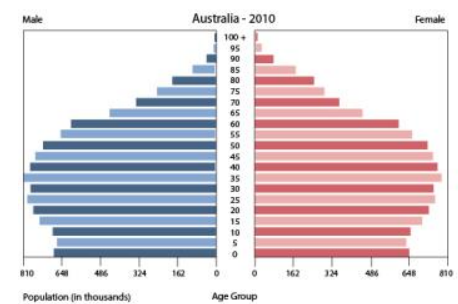

G

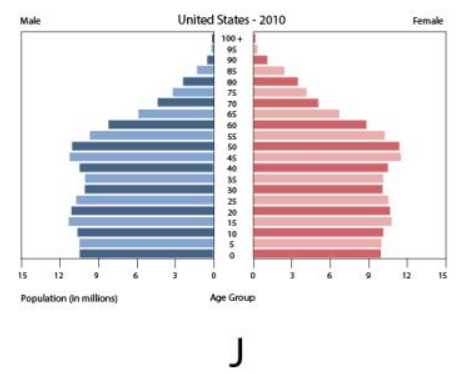

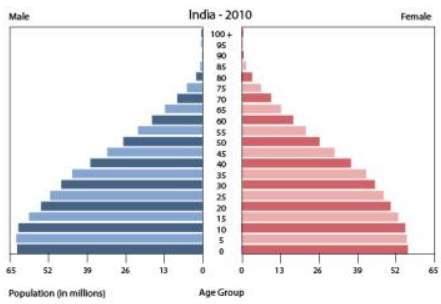

B

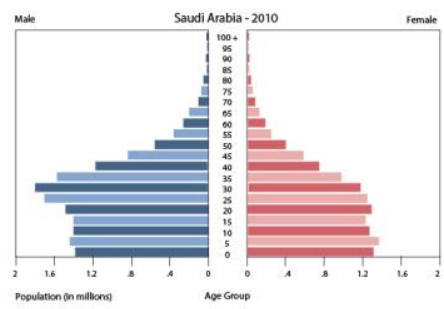

$\mathrm{E}$

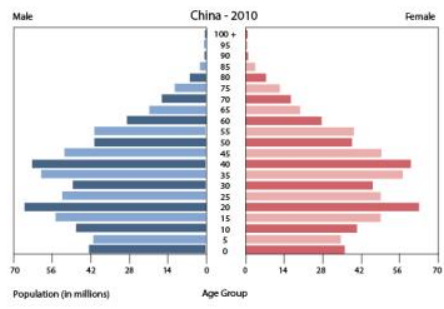

$\mathrm{H}$

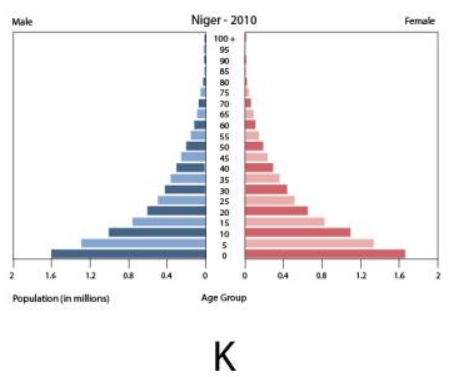

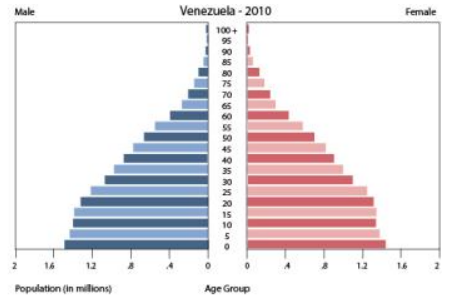

C

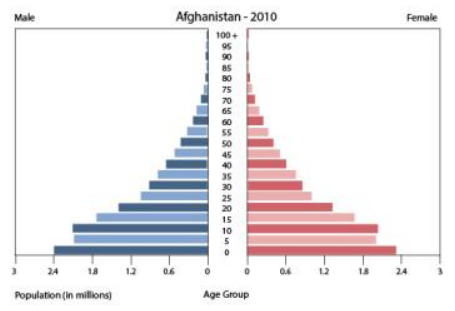

$\mathrm{F}$

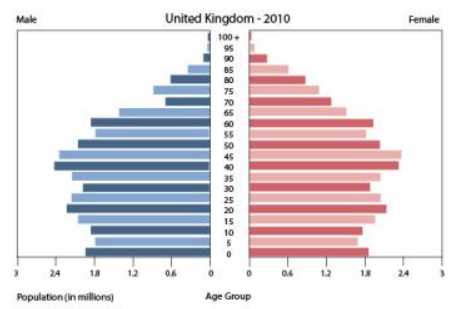

I

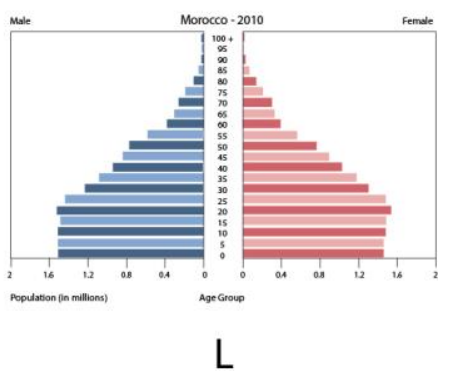

Figure 1. Population pyramids for twelve different countries in 2010. A; Haiti, B: India, C: Venezuela, D: Russia, E: Saudi Arabia, F: Afghanistan, G: Australia, H: China, I: United Kingdom, J: United States, K: Niger, and, L: Morocco. Source: U.S. Census Bureau. ${ }^{2}$

${ }^{2}$ https://www.census.gov/data-tools/demo/idb/informationGateway.php 
Almost none of our nearly two dozen teachers were familiar with the population pyramid representation, so we provided them with an annotated population pyramid which can be created using tools from the US Census Bureau website ${ }^{3}$ that provides background information on population pyramids to help them answer the initial question (Fig. 2). Once a group arrived at an answer, we had them lead a discussion around the reasons for their choice of which image in Figure 1 best fit China. We then introduced participants to a tool for producing population pyramids and other statistical visualizations, MERLIN ${ }^{4}$, which is associated with the BioQUEST project called Biological Excel Simulations and Tools for Exploratory Experiential Mathematics (ESTEEM) ${ }^{5}$.

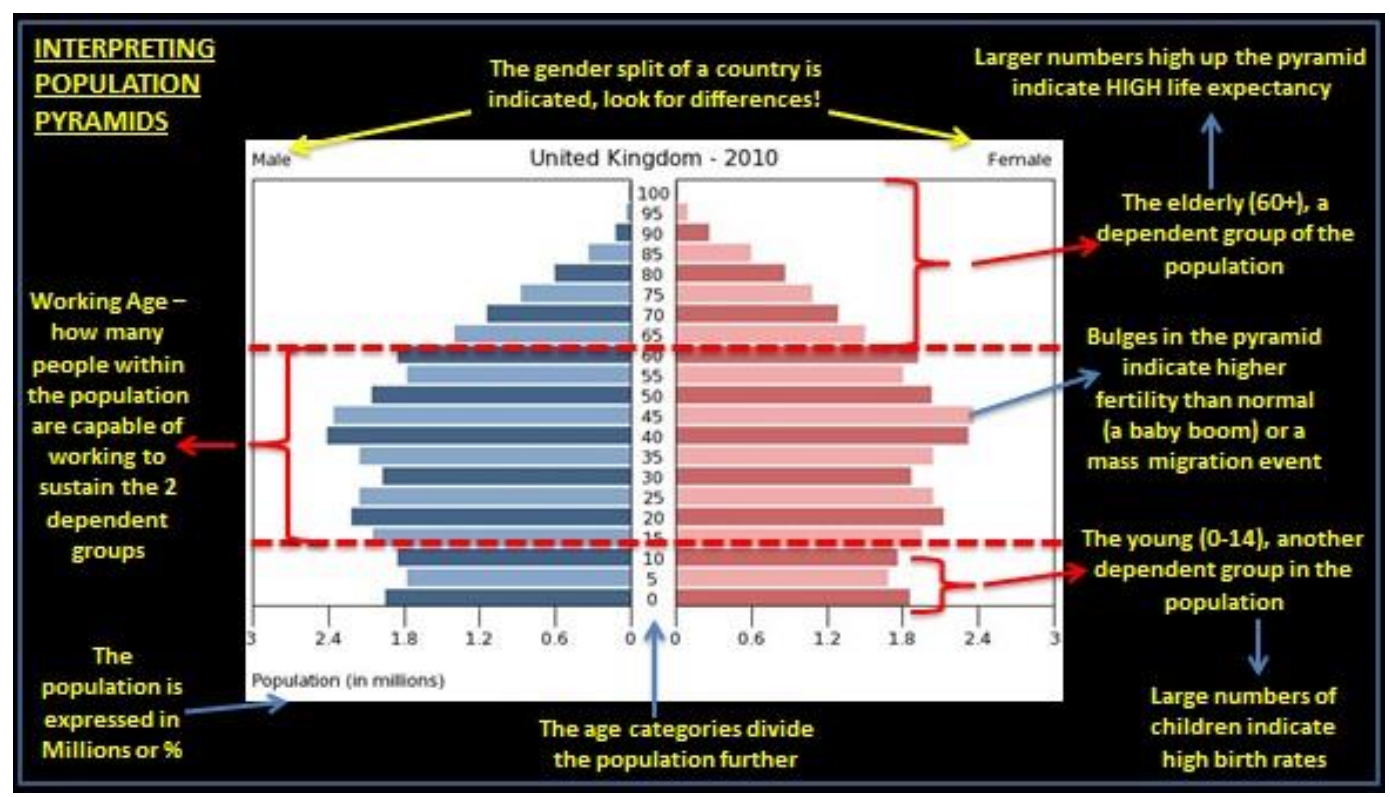

Figure 2. Interpretive guide to a population pyramid. Source: Rob Gamesby, developer of CoolGeography. ${ }^{6}$

Another resource addressing quality of life issues from Hans Rosling's four categories of contemporary living conditions could be introduced at this juncture to further humanize the discussion in terms of the realities of people's living conditions in these different countries (Fig. 3).

\footnotetext{
${ }^{3}$ https://www.census.gov/data-tools/demo/idb/informationGateway.php

4 https://www.stem.org.uk/resources/elibrary/resource/33426/merlin

$5 \mathrm{http}: / /$ bioquest.org/esteem

${ }^{6}$ http://www.coolgeography.co.uk/GCSE/AQA/Population/Population\%20Pyramids/Population\% 20Pyramids.htm Used with permission of the author.
} 
LIFE ONTHE FOUR INCOME LEVELS
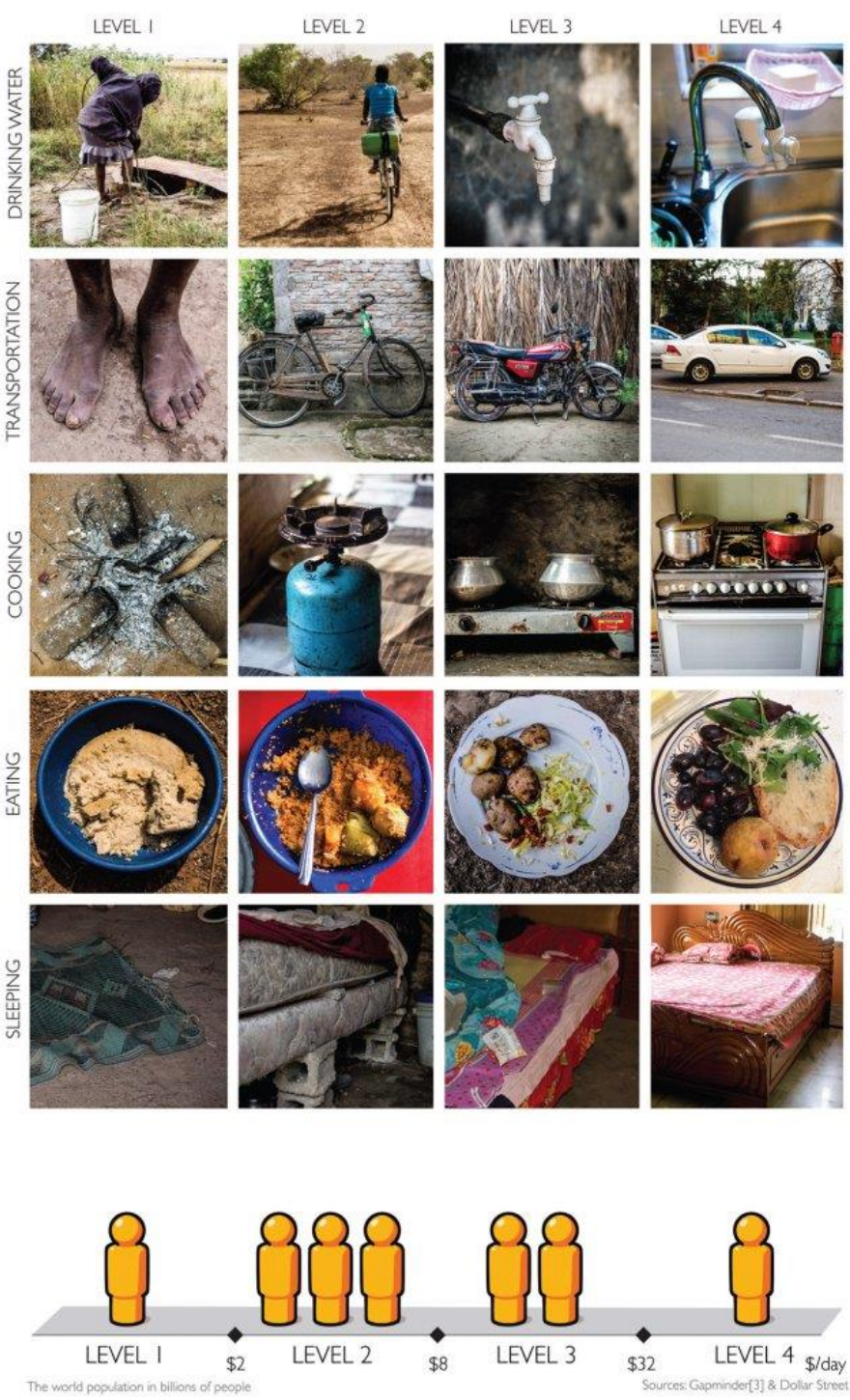

Figure 3. Hans Rosling's four categories of contemporary living conditions in different parts of the world. Source: gapminder.org.

\footnotetext{
${ }^{7}$ https://twitter.com/paimadhu/status/1008362445914693637 Used with permission of the author. (Also see https://readingraphics.com/uploads/2018/09/Factfulness_4-Levels-ofIncome.jpg and https://larryferlazzo.edublogs.org/files/2016/10/dollarstreetstreet2es78p7.jpg.)
} 
In order to advance the discussion on population policy in China, and, in particular, how each proposed policy might affect the future population size of China, we asked the high school teachers, now divided into the four policy subgroups, to build a mathematical model to predict the consequences of their assigned policy. Since these lessons were to be used with high school students, in U.S. grades 9-12, we anticipated that these initial models might be mathematically simple and a great starting point for the introduction of additional resources and real-world data.

Toward that end, we gave teachers a module from Core-Plus Mathematics: Contemporary Mathematics in Context Course 1 (Hirsch et al. 2008). This integrated curriculum, blending together concepts in algebra, geometry, and statistics in real-world contexts, was developed by the Core-Plus Mathematics Project at Western Michigan University with funding from the National Science Foundation. Four publications from their research group are relevant to our integrated, interdisciplinary work-Dupuis et al. (2012), Harwell et al. (2012), Post et al. (2012), and Grouws et al. (2013) - because they all stress the importance of interdisciplinarity in addressing complex, real-world problems. One of the authors of this paper has found the problem as presented in this text to be quite effective at engaging a wide range of groups from school district board members to at-risk high school students and was eager to use it again in the context of a more fully articulated lesson on population growth and modeling.

The Core-Plus unit on probability simulations sets the context and probes assumptions about the content as follows:

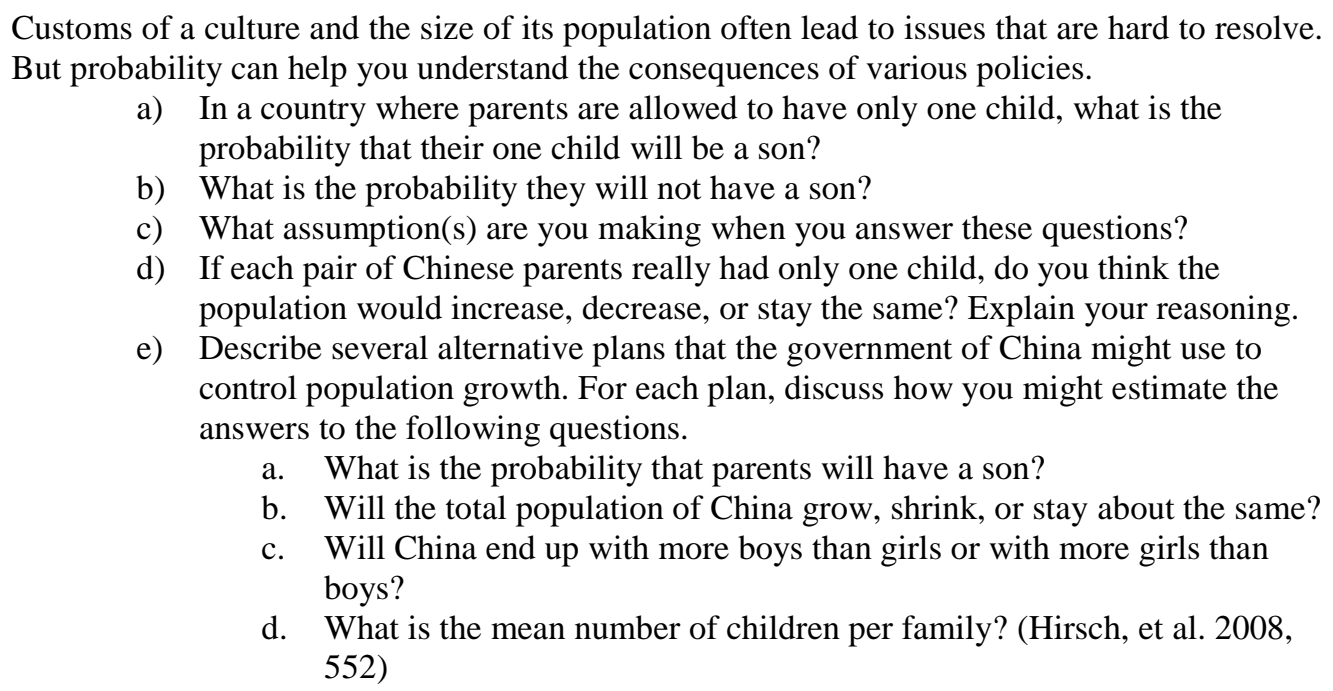

In presenting this problem, we highlighted a few mathematical concepts that we believed might be helpful for our participants to think about, including: 
1. Probability of independent and mutually dependent events

2. Binomial distribution (participants had previously conducted a Galton board activity)

3. Permutations versus Combinations

4. Law of Large Numbers

5. Linear versus Exponential versus Logistic Growth

We then asked teachers to place their model on the wall and discuss their group's approach applied to China's population's future (Table 1). One of the questions that frequently arises in discussions of problems such as this is related to sex ratio. It turns out that combinatorics involved with these probabilities and misconceptions that confuse possibility and probability were common. Thus, we shared information on a family that had 11 daughters. We had the teachers build and use Galton boards (Fig. 4) to understand binomial distributions and how Pascal's triangle relates to the distribution of male and female children in individual families.

Table 1.

Model of "son and done" developed by teachers

\begin{tabular}{|c|c|c|c|c|}
\hline \multirow[t]{2}{*}{ Generation } & \multicolumn{2}{|c|}{100 Mothers } & \multirow{2}{*}{$\begin{array}{c}\text { \# of Families of } \\
100 \text { total }\end{array}$} & \multirow{2}{*}{$\begin{array}{l}\text { With x\# } \\
\text { Children }\end{array}$} \\
\hline & Sons & Daughters & & \\
\hline 1 & 50 & 50 & 50 & 1 \\
\hline 2 & 25 & 25 & 25 & 2 \\
\hline 3 & 12 & 13 & 12 & 3 \\
\hline 4 & 6 & 7 & 6 & 4 \\
\hline 5 & 3 & 4 & 3 & 5 \\
\hline 6 & 2 & 2 & 2 & 6 \\
\hline 7 & 1 & 1 & 1 & 7 \\
\hline 8 & & 1 & 1 & 8 \\
\hline Subtotal & 99 & 103 & & \\
\hline $\begin{array}{c}\text { Total children }= \\
202\end{array}$ & $\begin{array}{c}\text { Children/mother }= \\
202 / 100=2.02\end{array}$ & $\begin{array}{l}\text { Which is less than } \\
\text { replacement level }\end{array}$ & 100 families & 202 children \\
\hline & & & & $\begin{array}{l}\text { Mean \# children/ } \\
\text { family }=2.02\end{array}$ \\
\hline
\end{tabular}

Our teachers discovered that the probability goes down simply by $1 / 2$ to the $n^{\text {th }}$ power where $n$ is the number of children; thus, the chances of having no sons is a monotonically descending series of probabilities: $n=1$, chance $=1 / 2 ; n=2$, chance $=1 / 4 ; n=3$, chance $=1 / 8 ;$ and so on through $n=11$, chance $=1 / 2048$. Thus, if we have enough families in our sample, even with eleven children, there is still the possibility of all daughters and no sons even though the probability is low. We loved the fact that several teachers, in addition to using Galton boards with their students, took the students to a gym and had sentinels stand at the apex of hexagons on a hexagonal honeycomb layout and flip a coin left or right as each student approached to see whether the students ended up at the other end of the 
gym in a near-to-expected binomial distribution. Readers interested in reading further about sex ratio may want to explore the "Trivers-Willard" hypothesis (e.g., Freese and Powell 1999; Cameron 2004; Kanazawa, 2005; Almond and Edlund 2007; Kanazawa 2007; Kaňková et al. 2007; Vellar et al. 2016; and Behie and O’Donnell 2018).
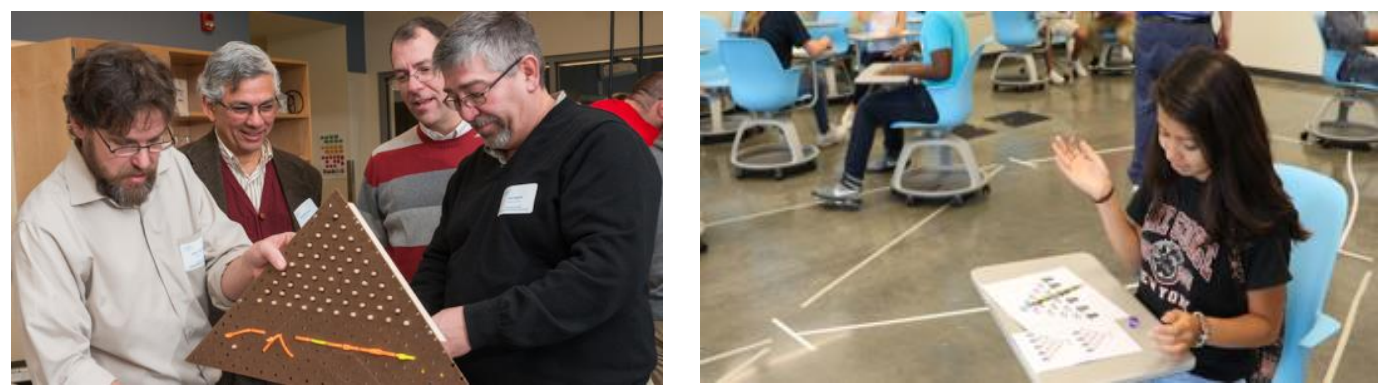

Figure 4. (Above) Teachers construct a Galton board to explore the binomial distribution, ISE Lab University of Delaware, January 2016; (Right) Students enact a binomial distribution, ISE Lab, June 2016.

Following the participants' presentations of their initial findings of the potential results of the four proposed population policies, both we and they introduced still more questions about biological considerations in interpreting population pyramids that might affect assumptions underlying each of the fundamental models. Some variables that the groups might choose to consider were also introduced. These included:
(a) Is 50/50 a realistic assumption?
(b) Do male and female children survive to reproductive age equally?
(c) What is the impact of infertility?
(d) What is the impact of homosexuality?
(e) What is the impact of birth control?
(f) What is the impact of delayed reproduction (30's and 40's primarily)
(g) What is the impact of IVF?
(h) What is the impact of epidemics and natural disasters (typhoons, floods, earthquakes, tsunamis, and drought)?
(i) What is the impact of female education, employment, and suffrage?

We asked teachers to look up data about those variables that they might use to change their model and introduced additional country-specific data by presenting a graph of birth rates in China over time (Fig. 5). This graph implicated both natural disasters and disastrous political policies in the precipitous decline of the Chinese population growth rate. The great famine caused by drought, weather, and some of Mao's draconian policies is easily visualized by the peak in death rate between 1959 and 1962 and the coupled drop in birth rate with unofficial estimates of the number of people dying during the famine varying between 20 
and 43 million (Smils 1999; Dikötter 2010). Additional interpretation of these data provided to our teachers took into account socioeconomic and cultural transformations of Chinese society: "As observed in many other countries and societies, socioeconomic and cultural transformations accelerated the pace of fertility decline. By the turn of the new century, China's fertility was well below the replacement level, and China began to face the mounting pressures associated with continued low fertility" (Feng et al. 2012, 84).

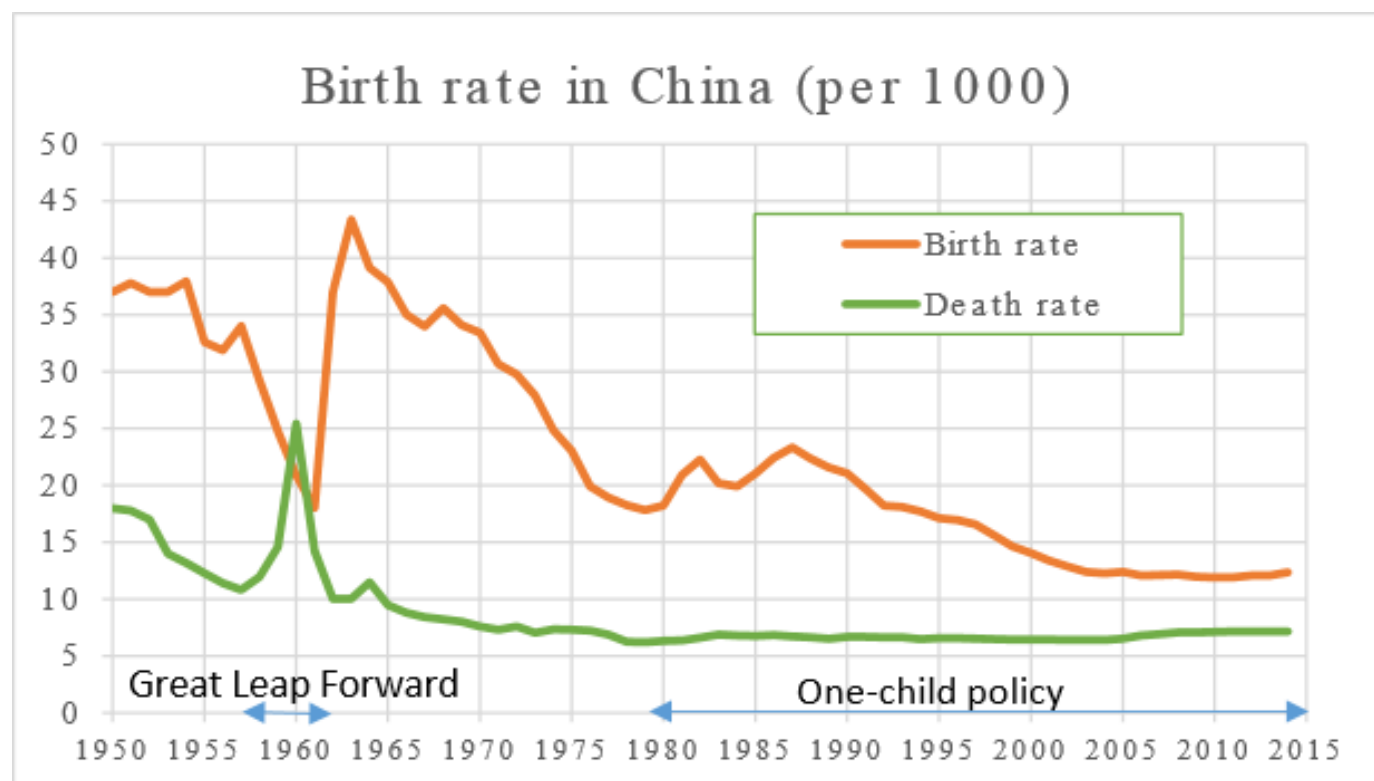

Figure 5. Birth rate in China, 1950-2015. The birth rate in China has decreased nonmonotonically over the 65-year period from 1950 to 2015. After the massive famine and major loss of life in the 1960s, there was a tremendous dip. Shortly thereafter, the one-child policy was introduced. From the mid-sixties until 2015, the death rate has stayed nearly constant. ${ }^{8}$

In addition to our attention to the births, Joyner $(2015,1)$ draws attention to the challenges in the growth of the upper end of the population pyramid in the near population:

It has been said that "demography is destiny" suggesting that at some level basic factslike the distribution of the population in different age groups - are key determinants of what happens to a given culture, country or even the world. That having been said, it is well known that the 'population is aging' and some have argued that the impact of aging on the world will ultimately be as big as the development of agriculture or the Industrial Revolution. I agree with this assessment and would add that aging is happening much

\footnotetext{
${ }^{8}$ https://upload.wikimedia.org/wikipedia/commons/thumb/1/1e/Birth_rate_in_China.svg/300pxBirth_rate_in_China.svg.png Used under creative commons license.
} 
faster and that we can see it coming in comparison [sic] the rise of agriculture and industrialization.

Even though the one-child policy was strictly enforced starting nearly a half century ago, the population has continued to grow as it takes nearly three generations to see the impact. In fact from 1980 to 2010, it grew from 1.0 billion people to about 1.4 billion people. Joyner (2015) developed about forty different projections of China's future population based upon multiple models [keep footnote link to graph source]. ${ }^{9}$ Most of his models predict that we are approaching an inflection in the growth curve such that the total population is likely to start decreasing over the next twenty to thirty years. His median model predicted that China's population would drop from its current size of about 1.4 billion people to about 1.2 billion people by 2100 . We then asked the four teacher groups which of these futures in Joyner's graph is consistent with their model. This question prompted still further elaboration of the groups' mathematical models and some surprising predictions about likely futures for China's population growth

\section{Possible Extensions of this Teaching Experience}

Frequently, our teacher participants were unfamiliar with many factors that influence the survival of children in their first five years. With all the advances in medicine, we routinely invest enormous medical resources in trying to save very low- (often premature) and very high-birth-weight newborns (Cavalli-Sforza and Bodmer 1971; Scriver 2004). In biology, survival versus human birth weight is often used as an example of stabilizing selection. The majority of newborn infants have a birth weight between 5.5 and 8.5 pounds (Scriver 2004). While modern medicine can save many premature and overweight babies, babies with birth weights less than 5 pounds and greater than 9 pounds have a very significant risk of dying before their first birthday. Often the death rate of infants is plotted as a log scale percent. (See Scriver 2004, Table 3 for a useful representation of the data. ${ }^{10}$ ) While there are genetic and hormonal causes of infant obesity that may affect some children, infant obesity is most often brought on by poor maternal diet and insufficient physical activity. There has, however, been a sudden rise in lowbirth-weight newborns with the current opioid crisis; many hospitals have separate units called Neonatal Therapeutic Units (NTU) to treat children born with Neonatal Abstinence Syndrome (NAS).

Note that the response to the investigation of China's one-child policy becomes complex rather quickly as population pyramids based upon societal and

\footnotetext{
${ }^{9}$ http://www.drmichaeljoyner.com/2015/01/

10 http://www.cmaj.ca/content/cmaj/171/12/1461.full.pdf.
} 
biological considerations are factored into the rather straightforward calculations of our binomial model.

Similarly, Rosling et al. (2018) note that major misconceptions about such societal and biological factors are shared by most well-educated people of the world:

Think about the world ... the number of poor keeps increasing; and we will soon run out of resources unless we do something drastic. At least that's the picture that most Westerners see in the media and carry around in their heads. I call it the overdramatic worldview. It's stressful and misleading. In fact, a vast majority of the world's population lives somewhere in the middle of the income scale. Perhaps they are not what we think of as middle class, but they are not living in extreme poverty. Their girls go to school, their children get vaccinated, they live in two-child families, and they want to go on holiday, not as refugees. Step-by-step, year-by-year, the world is improving. Not on every single measure every single year, but as a rule. Though the world faces huge challenges, we have made tremendous progress. This is a fact-based world view. (13)

Rosling et al.'s counternarrative directly addresses a major misconception about the growth of the human population. This misconception is explained through Donna Haraway (1997)'s narrative about a racist interpretation of which groups have more babies according to an evolutionary model based upon a logistic mathematical model.

The S-shaped curve of population growth (typically formed from a logistic model) is marked by rapid initial growth (given by $r$, the intrinsic rate of growth), and then a leveling off when the population reaches a carrying capacity $(K)$. This model is dependent upon two variables instead of just one. The logistic model is usually expressed as a differential equation which assumes continuous time and that the rate of increase or decrease in population size $N$ with respect to time is multiplicatively dependent upon the values of both $r$ and $K$, as well as the population size $N$ at that instant in time:

$$
\frac{d N}{d t}=r N\left(\frac{K-N}{K}\right)
$$

Haraway noted the implicit racism associated with a perverse interpretation of the logistic model and argued that some students may not have difficulty with the mathematics but may have been disturbed by the inferences associated with the equation. Note that $r$ - $K$ pairs that might result in higher or lower birth rates are affected by ecological and economic circumstances, the impacts of modern medicine, and genetic selection. ${ }^{11}$ Haraway points out how people who have a

\footnotetext{
${ }^{11}$ Despite Haraway's careful analysis, the reader can easily find blogs that continue to misappropriate the evolutionary ecological model of $r$ versus $K$ strategies of parental investment to support racist imaginaries.
} 
racist interpretation of this logistic equation have made spurious stereotypes that are clearly inconsistent with Rosling et al.'s (2018) actual analysis of the data:

In the U.S. imperialist imaginary, societies "down there" relative to the United States, in the warm and sordid regions of the planet, seem to have lots of human beings who act like r-strategists. The colder, more cerebral, less genital climes of the north-if one discounts immigrants of color and other nonprogressive types common in racist imagery - are replete with good K-strategists. (Haraway 1997, 204)

As interest and time permit, if participants want to explicitly explore the role of varying $\mathrm{r}$ and $\mathrm{K}$ in logistic models, then they can import data on a population over time into a spreadsheet available from the BioQUEST ESTEEM project's "Continuous Growth Models" module ${ }^{12}$ (Fig. 6) to determine whether their data are more consistent with a linear, exponential or logistic model.

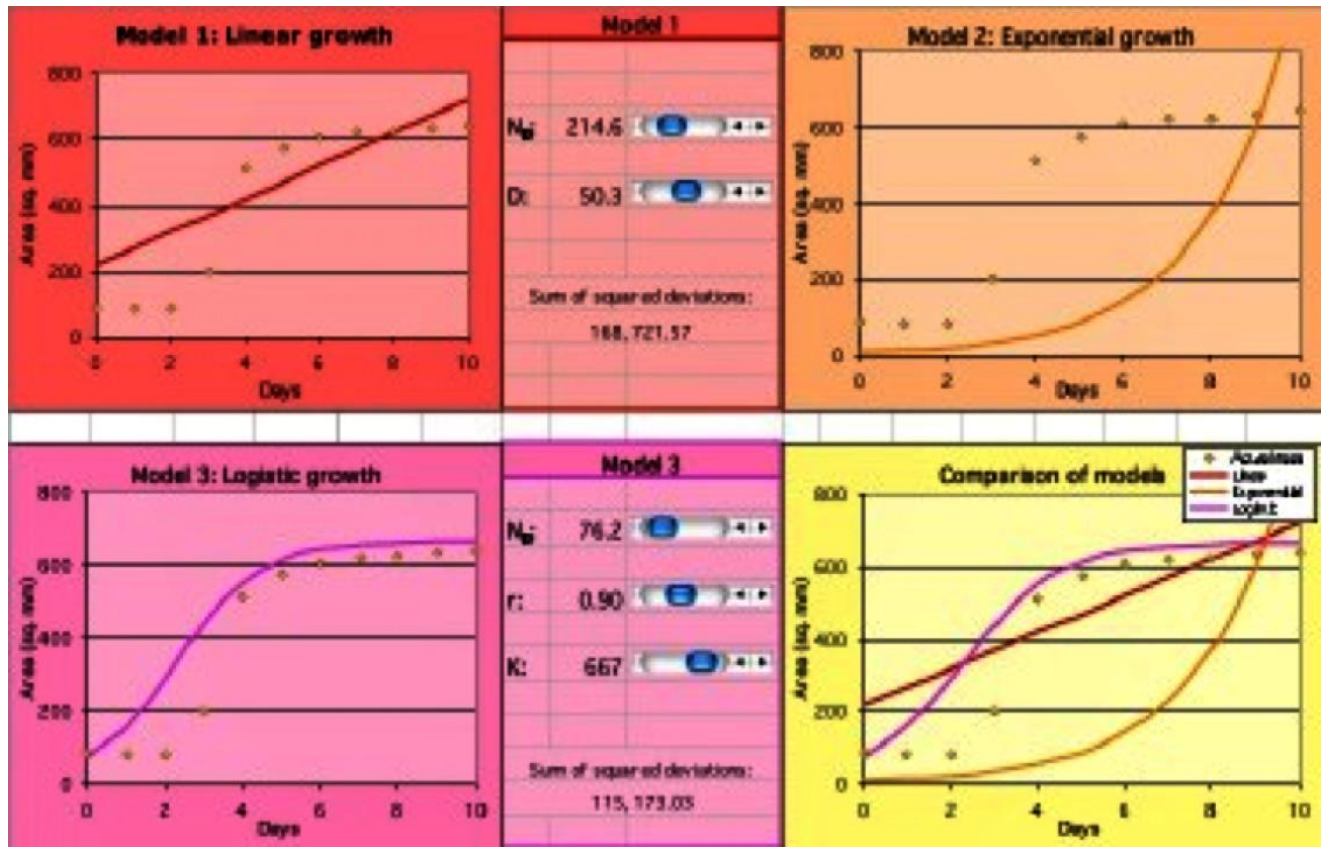

Figure 6. Three models of population growth. The Biological ESTEEM module on population growth allows the user to enter their raw data and then the spreadsheet will generate the best fit to the empirical data based upon three different models: linear, exponential, and logistic.

This exploration could go as far as the instructor and students are willing to take it. For example, educational spreadsheet matrix models for age- or stagestructured populations are available (see BioQUEST ESTEEM Leslie/Lefkovitch module). Also, the logistic model is famous because it easily generates chaos. For an excellent introduction to chaos in the logistic model in a spreadsheet with chaos and cobweb graphs see the talk by David McAbidy with the Washington

\footnotetext{
${ }^{12}$ http://bioquest.org/esteem/esteem_details.php?product_id=197
} 
Center for Improving the Quality of Education at the Evergreen State College. ${ }^{13}$ An investigation can also be left open to be returned to at a later date as interest and increasing mathematical and scientific sophistication permit.

\section{A Most Surprising Result}

Our pedagogical emphasis throughout was to engage teachers with progressively nuanced data and increasingly sophisticated models. We ended our workshop on global population modelling with Hans Rosling's (2012) TED talk video "Religion and Babies." ${ }^{14}$ It doubly serves as a humanistic, fact-based alternative narrative that counters the assumption that certain religions (e.g., Catholicism and Islam) are responsible for women having more babies than those of other religions (e.g., Protestantism, Judaism, and Secular Humanism) and visually demonstrates the power of mathematical modeling. Using a multivariate representation, Rosling shows that as we improve neonatal infant mortality, the economic and educational status of women, the availability of clean water, and widespread vaccination, the number of children per woman actually goes down to replacement level (i.e., between 2.1 and 2.3 children per pair of adults depending upon health variables) independent of religion (Fig. 7). His Gapminder graph represents per capita income on the abscissa, fertility rate on the ordinate, population size as the size of each data circle, and dominant religion as the color of these circles. When the graph is set in motion, a fifth variable of time is introduced. That Rosling's video has been viewed well over two million times is consonant with the inference that this issue is timely and resonant.

The variety of images we introduced during this workshop present similar data in different ways, and they allow teachers and students to analyze arguments by turning to data as a resolution to otherwise thorny problems. Tools like spreadsheets and statistical packages enable and encourage the development and testing of models and allow for a civil discourse about difficult issues. We include one more inherently dynamic graphic to address the difficult issues above: Rosling's Gapminder image of the trajectory of eight different countries' progress in both decreasing the number of children per woman correlated with the improvement of literacy in those same nations (Fig. 8). Note that all countries regardless of the predominant religion-Asian (notably, China and India), Islam (Indonesia and Turkey), and Catholicism (Mexico) - reduced their number of children per woman significantly over the past forty to fifty years as the literacy rate of adult females increased; in particular, note that several countries have dropped below replacement levels over this period.

\footnotetext{
13 https://slideplayer.com/slide/5012822/

${ }^{14}$ https://www.ted.com/talks/hans_rosling_religions_and babies?language=en
} 


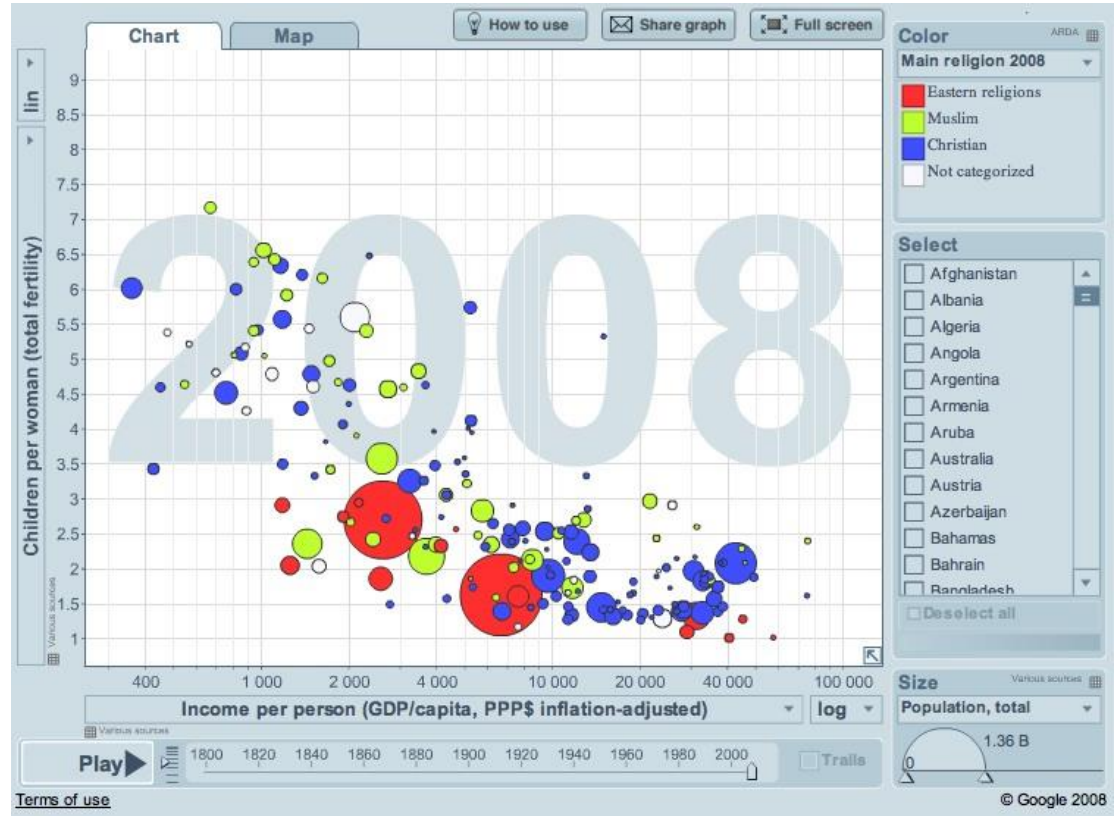

Figure 7. Hans Rosling's Gapminder graph illustrating that when income per person rises to about $\$ 2,000$ per year, the fertility rate on average drops to about two children per woman. ${ }^{15}$

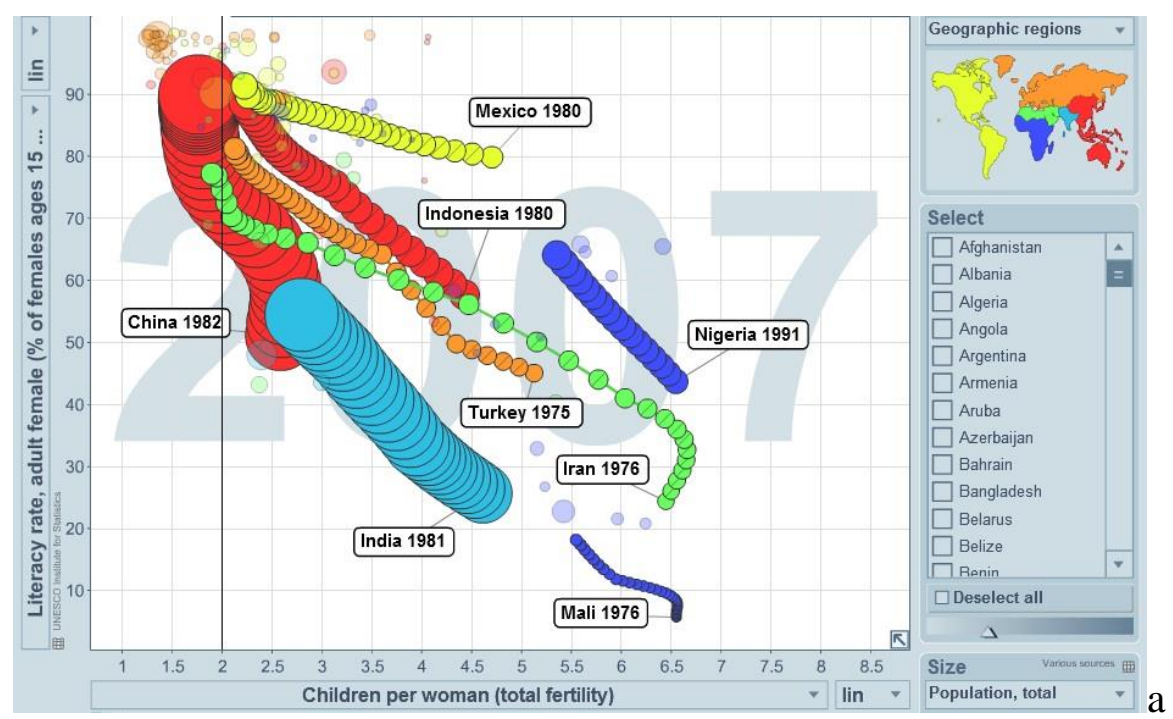

Figure 8. Literacy versus children per woman. Source: Gapminder. ${ }^{16}$

\footnotetext{
${ }^{15}$ https://braddlibby.files.wordpress.com/2012/04/tfr-vs-income-by-religion.jpg. Used under creative commons license.

${ }^{16}$ Used under creative commons license.
} 
Another surprise to us was that, while the focus of this experience was on China, once participants understood the population pyramids, they wanted to look at how the U.S. population pyramid was apt to change over their lifetimes. Our teacher participants worried about Social Security, Medicare, Medicaid, and the Affordable Care Act. That topic broached an existing controversy between economists; the debate concerns whether the challenge of caring for an aging population is a demographic dividend or a demographic dilemma (Kotlikoff et al. 2007; Bloom et al. 2009; Cai 2010; Lee and Mason 2006; Lin 2015).

Although we did not attempt to introduce all of the concepts and tools (e.g., BioQUEST ESTEEM modules, Excel, GapMinder, JMP, Merlin, WorldMapper) described in the preceding section during our initial explorations with high school teachers, their feedback indicated that they found the problem to be thoroughly engaging and profoundly meaningful. They considered the results of their initial analyses surprising on many levels.

The fact that the "son-and-done" model would, with simplified assumptions, result in zero population growth and equal numbers of female and male babies, seemed counter intuitive to many of our teachers. One group that developed this model demonstrated the convergence to an equal number of male and female children just by considering one hundred families and the distribution of families ranging from one to eight children. That the infinite progression of

$$
\frac{1}{2}+\frac{1}{4}+\frac{1}{8}+\frac{1}{16}+\ldots+\left(\frac{1}{2}\right)^{n}
$$

would sum to one in the limit (with the implication that on average there would be a mean of one female child per family) ultimately made sense to participants but seemed to contradict the observation that families would have one and only one male child ("son and done") but might have, with diminishing probability, quite a few female children before that first male child was born. The fact that this result was so startling went a long way in convincing most of our teacher participants that a careful approach to mathematical modeling was essential in order to help "read the world" with any real confidence.

The Rosling Ted Talk, with which we concluded our winter workshop sessions, was likewise provocative and demonstrated that even life-and-death problems on the largest scale were not impervious to the application of scientific reasoning or mathematical modeling. We might also note that the wealth of visual representations from population pyramids to Rosling's five-dimensional Gapminder graphs (most were quite novel to our teachers) provided multiple modes of access to the data-rich population problem. Perhaps most importantly, this problem-based learning experience convinced at least some of our participants that issues of social justice could, and probably should, occupy an important place within their STEM curriculum. 


\title{
Exploration Two, Teaching the Taboo: Ignorance as an Invitation to Explore in a Brave Space
}

In the first professional development teaching experience above, we employed two principal tools: (1) modeling based on a set of simplifying assumptions and examining how modeling often leads to counterintuitive results that enable reexamination of those assumptions; and (2) using population pyramids to examine how capturing a demographic distribution at one point in time can be used to infer how age cohorts move from one age category to another and can be used to make inferences about how the proportion of births, children, juveniles, adults, and seniors are influenced by policies, war, famine, immigration, and cultural considerations. This approach worked well in the context of a two-day workshop. In our second professional development teaching experience, we had the benefit of a semester-long graduate course to choose among multiple choices, to do readings, develop new skills, perform analyses, have discussions, and promote follow-up research. We presented to students three quantitative cases for exploring aspects of social justice in the U.S.: (1) gerrymandering, (2) fair voting practices, and (3) slave breeding in the $19^{\text {th }}$ century. The students (who were experienced teachers) chose the third possibility for a "brave space," noting that the topic is usually taboo in their classrooms and that they had the least prior knowledge about this practice. They felt that it would engage many of their students, and the data set was less overwhelming and more defined than that of the other two possibilities. The instructor also wanted to explore a different quantitative approach that would engage the teachers in exploring and examining data with alternative visualizations of patterns in a data set, as well as learning about the power of exploratory data analysis.

\section{Slave Breeding in the American South from 1808- 1864}

\author{
The Slave Auction \\ By Frances Ellen Watkins Harper \\ The sale began-young girls were there, \\ Defenseless in their wretchedness, \\ Whose stifled sobs of deep despair \\ Revealed their anguish and distress. \\ And mothers stood, with streaming eyes, \\ And saw their dearest children sold; \\ Unheeded rose their bitter cries, \\ While tyrants bartered them for gold.
}



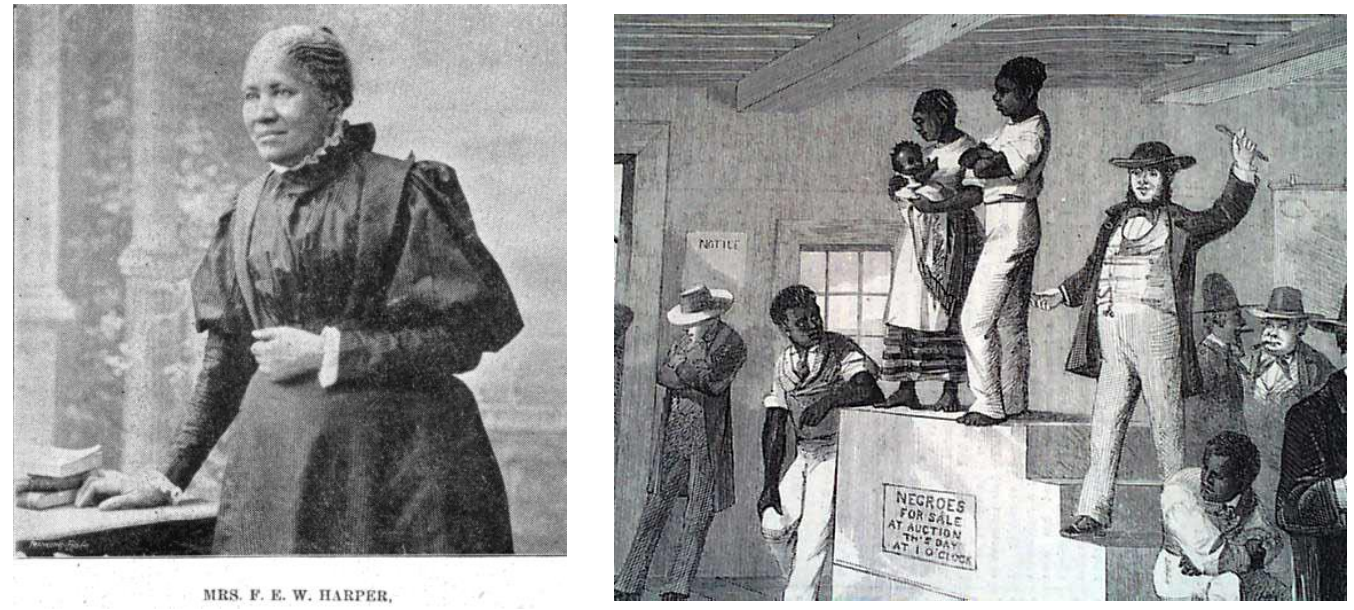

Figure 9. (Left) Portrait of Frances Ellen Watkins Harper. Frances Ellen Watkins Harper was an early African American civil rights activist, poet and author. She lived from September 24, 1825 to February 22, 1911. ${ }^{17}$ (Right) An Auction of Slaves. The biggest auction of slaves took place on March 3, 1859. "The 436 men, women, children, and infants, all of whom had been born on [Pierce M. Butler's] plantations, were brought to a racetrack in Savannah, Georgia, and put in the stalls used for horses. There they waited, some for days, others for weeks, for the auction to begin. ... It was the largest sale of slaves on record in the United States, and it was referred to as 'The Weeping Time."”18

As part of a graduate course for teachers led by Jungck entitled "Beyond Two Cultures," in the section on mathematics and social justice, students watched the movie Hidden Figures ${ }^{19}$ and read Robert Moses and C.E. Cobb's (2001) book, Radical Equations: Civil Rights from Mississippi to the Algebra Project. When the instructor presented three cases for students to choose one fromgerrymandering, fairness of alternative voting schemes, and slave breeding - he was surprised that the students were most interested in pursuing the case of slave breeding, even though a priori it seemed the most socially difficult of the three cases for civil discussion. Part of this approach was dependent upon the problemposing approach of Paulo Friere (1968) as developed in mathematics education (Cunningham 2004; Van Harpen and Presmeg 2013; Brown and Walter 2014; Cai, et al. 2015; Jungck and Roy 2014; and Gutstein 2018) and biology education (Jungck 1985; Dolan and Collins 2015; Liao and Chang 2016.) In this teaching experience, the teachers were presented with historical data and powerful statistical tools (the statistical software JMP).

Why tackle a "taboo" subject, perhaps one that is even more challenging in contemporary America than our earlier workshop on population dynamics? The

\footnotetext{
${ }^{17} \mathrm{https}: / /$ en.wikipedia.org/wiki/Frances_Harper.

${ }^{18}$ http://www.americaslibrary.gov/jb/reform/jb_reform_slaveauc_1.html.

${ }^{19}$ https://en.wikipedia.org/wiki/Hidden_Figures
} 
historian Ira Berlin (2004) states our current difficulty in dealing with the issue of slavery:

Those troubled cases demonstrate that the discussion of slavery is not easy. Even as slavery serves as a surrogate for race, it too becomes tangled in the very same emotional brier patch. For slavery, like race, also carries with it deep anger, resentment, indignation, and bitterness for some and embarrassment, humiliation, and shame for others, along with large drafts of denial. Almost 140 years after slavery's demise, the question still sits on tender and sensitive ground. It is so sensitive that many Americans cannot even say the word. For some, it is "servants" or "servitude," a recognition of subordination, but an obfuscation of the slave's unique status as property; for others, it is "enslaved people," or more awkward still, "enslaved circumstance," a recognition of the slave's humanity and a pointed denial of the slave's consent to enslavement, but a similar beclouding of the unique meaning of property in man. As the struggle over nomenclature reveals, Americans feel the need to address the subject of slavery, to understand it, but they do not exactly know how (1260).

The teachers reported that having such discussions about slavery with their students was scary and risky, but that the legacy of slavery was often the subliminal issue behind many assumptions that students had about civil rights issues such as affirmative action. As Deborah Howett, a journalism professor, (personal communication) has said: "The increase was the direct result of social, economic and political conditions that promoted the utter degradation and inhuman treatment of enslaved people as a farm crop or commodity." Thus, as Berlin noted, students did not know how to address the issue and were curious whether there might be a very different way to engage students about slavery without having to lecture about the content beforehand. So even if we "do not exactly know how" to deal with such a difficult issue, we believe that a careful analysis of the data at least allows students a way to examine this issue and to be able to discuss this and other difficult issues that persist.

Bob Peterson is a mathematics educator who studies young children and who has explicitly dealt with them on issues of slavery and racism. He reports on children's resentment of not being respected sufficiently to deal with aspects of history:

In subsequent days, some students wrote letters to the textbook publisher. Michelle, a white girl, was particularly detailed. She wrote: "I am 11 years old and I like to read and write. When I am reading I notice every little word and in your social studies book I realize that the word "racism" is not in your book. You're acting like it is a bad word for those kids who read it." She went on to criticize the book for not mentioning that any presidents had slaves: "I see that you do not mention that some of the presidents had slaves. But some of them did. Like George Washington had 317 slaves. So did Thomas Jefferson. He had 267 slaves." She continued: "If you want to teach children the truth, then you should write the truth. $(2013,232)$

In the context of social justice issues involving population growth for our work with teachers, we argue that not only can we look at the data on population 
demography of slavery in the U.S., but that the importance of using mathematics is as useful in examining what happened in the past as it is in predicting the future. Thus, we developed an experience focusing on the highly controversial topic of "slave breeding" as it occurred in the period between the end of legal importation of slaves and the emancipation proclamation. Table 2 and Figure 10 provide data on the U.S. population size of slaves from the end of legal importation to the Civil War.

Table 2.

American Slave Population Figures, 1790-1860

\begin{tabular}{lc}
\hline \hline Year & Slave Population \\
\hline 1790 & 694,207 \\
1800 & 887.612 \\
1810 & $1,130,781$ \\
1820 & $1,529,012$ \\
1830 & $1,987,428$ \\
1840 & $2,482,546$ \\
1850 & $3,200,600$ \\
1860 & $3,950,546$ \\
\hline \hline
\end{tabular}

Note: The slave population increased by 2,819,765 people, a nearly $250 \%$ increase in fifty years, and an average of 56,935 people annually. Source: William A. Percy, "An Antebellum Dilemma Uncovered.,20

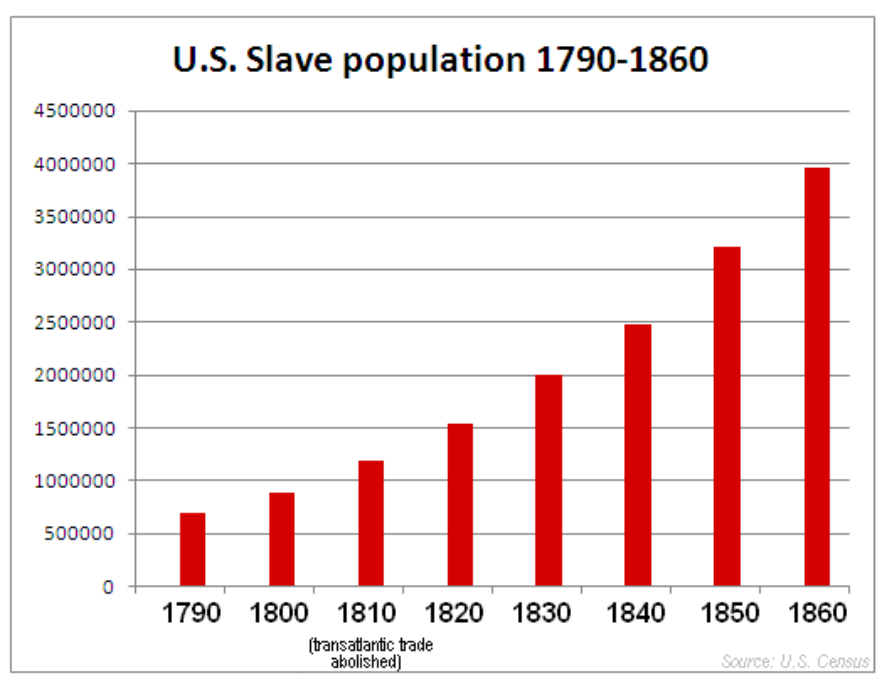

Figure 10. The slave population in Table 2 plotted in ten-year intervals from 1790 to 1860.

The teacher showed the students how to export this data into the statistical package JMP and to perform a quadratic fit (Fig. 11). We also had a discussion about linear, exponential, and logistic growth as shown earlier in Figure 6. The teachers were comfortable with the notion of population doubling, and we used this notion to build an understanding of how a quadratic fit related to the notion of doubling. JMP was advantageous because once students chose a model, the

${ }^{20}$ http://www.williamapercy.com/wiki/index.php/An_Antebellum_Dillemma_Uncovered 
software fitted the chosen model automatically. It also allowed them to easily explore other models.

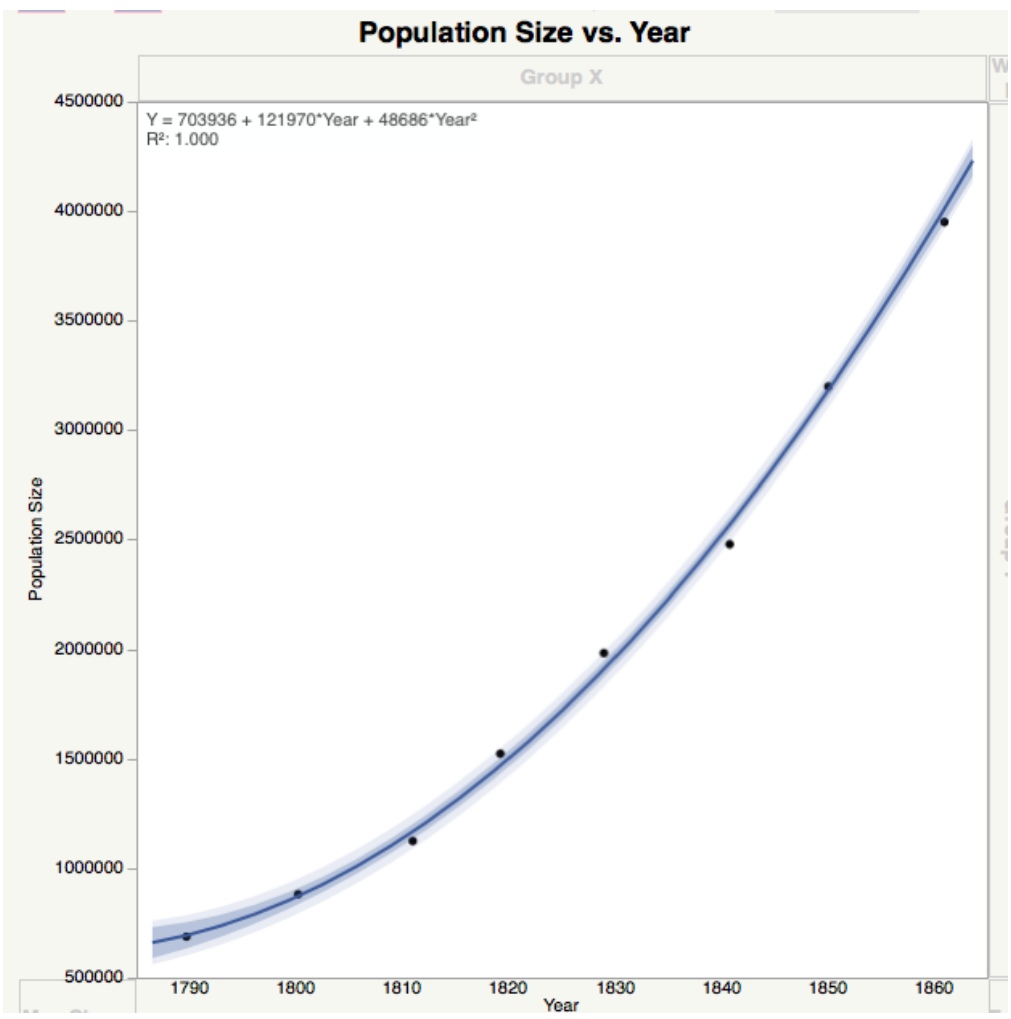

Figure 11. A quadratic fit to the data in Table 2 performed in the statistical package JMP. Note the expected concave upward trend in the graph of the growth in the population size of slaves over the seventy-year period. Note also that these authors have never seen an $R$-squared value of 1.000 for actual data in their extensive experience. Obviously, the trend line is highly nonlinear and is easier to see than in the histographic representation in Figure 10. This regression analysis also has the benefit of being predictive, as well as providing additional quantitative information such as a quadratic equation of the form $y=c+a x+b x^{2}$.

In order to explore the importance of births in building the population, the teachers were asked to examine how many slaves were born in each time interval. Without invoking calculus and the notion of a delta, we still could look at the number of individuals added to the population during each time interval. Thus, by re-plotting the data (Table 3), we can look at the increase in population size over this time interval (Fig. 12). 
Table 3.

Examining the Change in the Recorded Population of Slaves in the U.S. that Occurred in Each Decade between 1790 and 1860.

\begin{tabular}{ccc}
\hline \hline Ten Year Time Interval & Difference in Census Population of Slaves & Years from Initial Date \\
\hline $1790-1800$ & 193,405 & 10 \\
$1800-1810$ & 243,169 & 20 \\
$1810-1820$ & 398,231 & 30 \\
$1820-1830$ & 458,416 & 40 \\
$1830-1840$ & 495,118 & 50 \\
$1840-1850$ & 718,058 & 60 \\
$1850-1860$ & 749,946 & 70 \\
\hline \hline
\end{tabular}

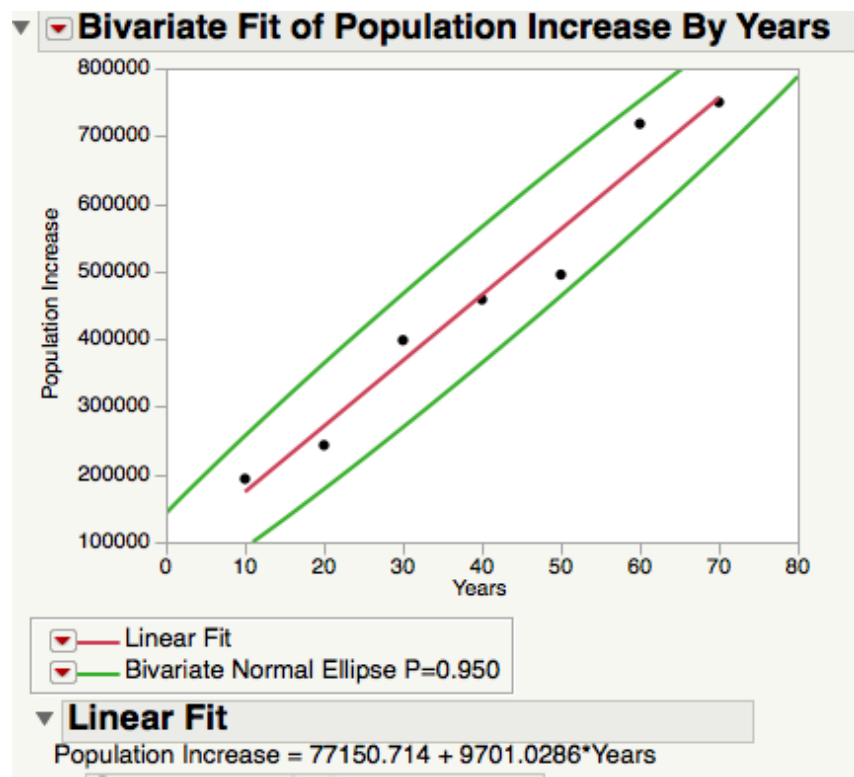

Figure 12. Bivariate fit of population increase census population of slaves by years following 1790. The data from the table were analyzed by a linear regression model in JMP. The linear regression line is shown in red and the 95\% ellipse is shown in green (Note that $100 \%$ of the data points fall within this narrow cigar-shaped ellipse). The resulting prediction was significant beyond the 0.0001 fiducial level.

These data and analyses were offered for consideration as the teachers were asked to model how many children women were producing over this time period of slave breeding. First, the teachers were asked what assumptions they needed to consider. In response, questions they raised included: What proportion of the population in 1808 (the end of legal importation) likely would have been female? What proportion of females were of reproductive age? What was the mortality rate of slaves prior to reaching reproductive age? Were there any improvements in overall health conditions over that interval that would allow more children to survive than before? Where was this process occurring? Related to this last question, they examined two important sources. First, in the U.S. they looked at 
the growth of the non-slave population. It was complicated to compare this growth to the growth of slaves because, while the importation of slaves was reduced to a very small level, the immigration of non-slaves was significant. Note that in the left map of Figure 13, the growth of slaves was not only below the Mason-Dixon Line but also present as part of an enormous westward expansion. This pattern surprised the teachers. Second, they were surprised to learn that the population of slaves in other regions of the New World (particularly Brazil and the Caribbean) significantly decreased in the period 1808-1865 and was not exponentially growing as it was in the U.S. despite the fact that fully $40 \%$ of the total number of slaves brought to the Americas went to Brazil, whereas the United States received only about $3.5 \%$. Between 1808 and 1888, more than a million new slaves were forcibly shipped to Brazil. Brazil depended more on importation than breeding; from 1845-1850, the number imported increased from 20,000 slaves per year to 60,000 slaves per year. We noted the interdisciplinary nature of the teachers' interests and questions here. We also reaffirmed the importance of the three imperatives that have guided the development of these teaching experiences (interdisciplinary, problem-based exploration, and that both context and content matter) as we described and exemplified them throughout.
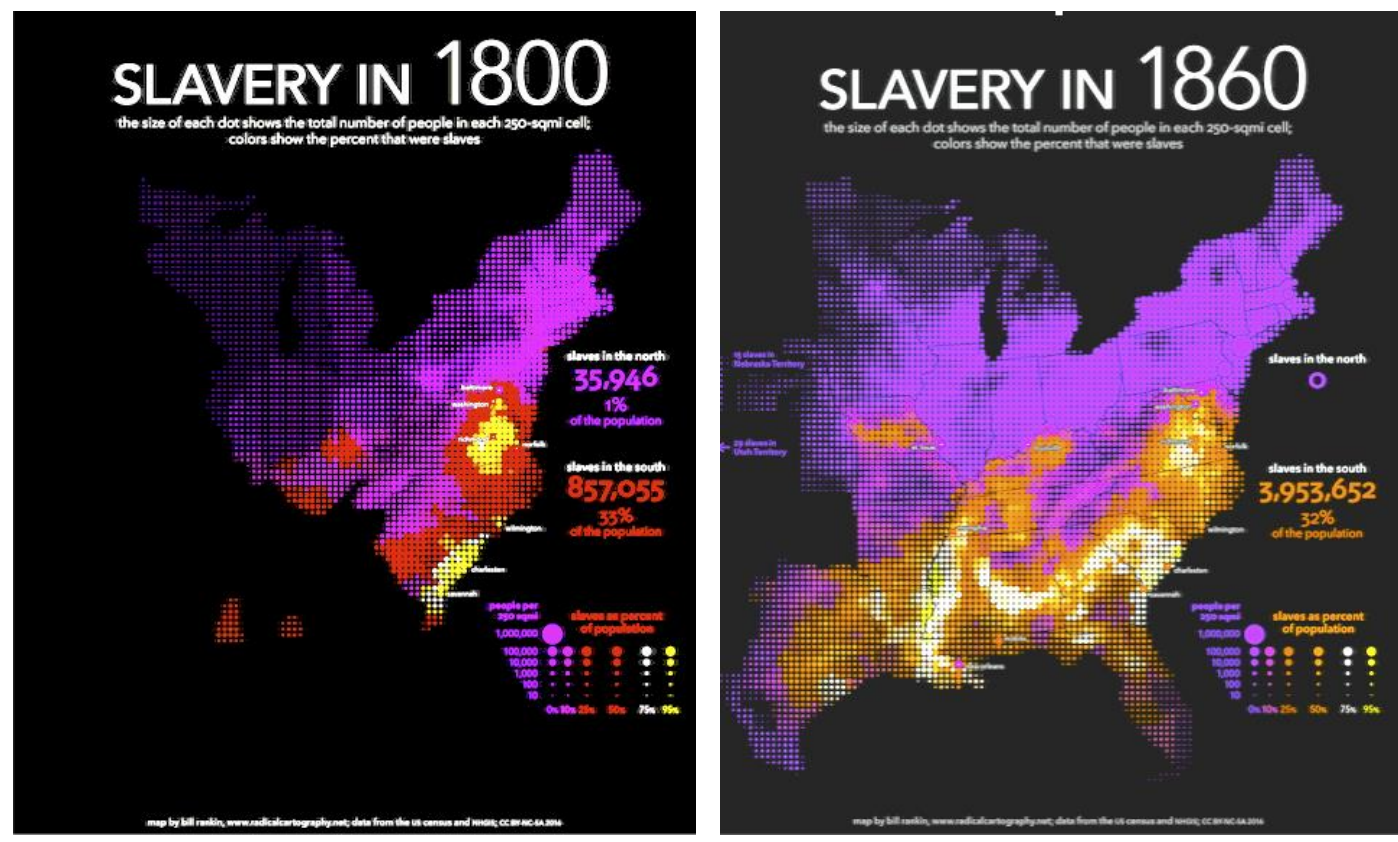

Figure 13. The U.S. distribution of slaves in (Left) 1800 and (Right) 1860 . Not only had the population of slaves dramatically increased, but the distribution of slavery was enormously expanded westward over this 60-year period. Source: American Slavery by Bill Rankin, 2016. ${ }^{21}$ Used under creative commons license.

${ }^{21}$ http://www.radicalcartography.net. Used under creative commons license. 
In examining the data from one region of Brazil in $19^{\text {th }}$ century Brazil (Fig. 16), one sees that almost all adult slaves in the population were of African origin. Only after the import of slaves was cut off (between 1820 and 1835) were there a significant number of children of slaves born in this region of Brazil. The reason that we looked for this data was because one of the teachers questioned whether the U.S. situation was any different from that of other slave-importing countries. Since Brazil was the largest importer of slaves in the New World, it seemed like the most relevant country for a demographic comparison. While it is obvious in the back-to-back plot in Figure 16 that young children were no longer imported into slavery in Brazil during the fifteen years before 1835, it is also clear that the majority of slaves in Brazil older than 20, both men and women, were born in Africa, and this pattern is in stark juxtaposition to the situation in the United States during that same period.



Figure 16. An 1835 population pyramid of slaves in the Santiago do Iguape Region Brazil who were African born or Brazilian born. Source: Bahia History Project: Reproduced with the author's (Julie Holt) permission. http://www.mappingbahia.org/project/maps-and.../populationpyramid-by-race-1835

The Gilder Lehrman Institute for the Study of Slavery, Resistance, and Abolition at Yale University posts an AP History Guide to American History ${ }^{22}$. On their page on the "Origins of Slavery" they state:

For much of eighteenth century, black people in South Carolina and Georgia-unlike those in Maryland and Virginia - resided in an immigrant society, more an extension of Africa than of Europe. With the slave trade open and the influx of "saltwater slaves" nearly continuous, lowland slaves had great difficulty forming families and reproducing e

${ }^{22}$ http://ap.gilderlehrman.org/essay/origins-slavery-0 
wonderful themselves. The gender ratio among the newly arriving saltwater slaves was usually dramatically skewed, and acculturated slaves sometimes were reluctant to create families with the new arrivals. But by the middle of the eighteenth century, the black population of the Lowcountry began to reproduce itself and the number of African Americans grew, although it did so in tandem with newly arrived Africans. If at midcentury slaves in the Chesapeake had few opportunities to converse with Africans, Africans and African Americans in the Low country knew each other well.

Thus, we might infer that something different was occurring in the $19^{\text {th }}$ century. In order to explore this question, the teachers decided to take the 1810 data as our closest value to the 1808 legislatively-declared termination of the importation of slaves (while historical records report that some slaves were still illegally imported to the U.S. after that date, migration into the U.S. was essentially shut down), then asked: How many years did it take to double the slave population? By simply interpolating from the graph, the population of slaves was $1,130,781$ in 1810 and a doubling would be equal to 2,261,562, and this occurred somewhere between 1830 and 1840 (less than 30 years). Since the data fit the quadratic line so well for the twenty years prior to the end of legal importation of slaves, the teachers asked whether we can infer that active breeding of slaves had already been occurring prior to the law's enactment.

This important period in American history and the terrible treatment of human beings in slavery lends itself to dealing with an important issue of social justice. The examination of quantitative data affords us the opportunity to explore the extent of the issue in duration in time, geographic spread, and magnitude of the population exposed to such injustice. In today's focus on the issues raised by the organization Black Lives Matter, ${ }^{23}$ we quote Simon (2016): "What might it mean to live our lives as if the lives of others mattered? One aspect of such a prospect would be our ability to take stories of others seriously, not only as evocations of responsibility but as well as matters of "counsel." (88). bell hooks (2003) further argues: "Teachers are often among the group most reluctant to acknowledge the extent to which white-supremacist thinking informs every aspect of our culture including the way we learn, the content of what we learn, and the way we are taught" (25). We feel that by using extensive data and powerful mathematical tools of analysis in a problem-posing approach it is possible to have an affordance of a brave space to deal directly with injustice, inequity, and history without generating reactions of denial, anger, shame, guilt, or irrelevance.

The teachers in this course had already developed respect for one another and one another's perspectives even before the fourth of four modules in the course, having dealt with issues of civil rights, social justice, racism, sexism, and conflicts

${ }^{23} \mathrm{https://blacklivesmatter.com/}$ 
between religion and science before dealing with this focus on slavery. Thus, it is not surprising that no major new conflicts developed amongst them, that they demonstrated curiosity, and that their discussions were civil and respectful. They discussed their own comfort level in dealing with brave issues in their own classrooms. To assess the impact of this examination of the history of slave breeding in $19^{\text {th }}$-century America, it is worth reporting that three of the class projects that the teachers developed on their own included: Faulkner and his novels' treatment of the legacy of slavery in Southern race relations, the success of individuals of African descent in marathons, and tracking in schools. All of these referred back to class discussions about the analysis of slave-population growth.

\section{Conclusion}

We respect the difficulties that teachers face in engaging their students in addressing issues such as population growth, family planning, responsible citizenship, and rectifying historical inequities. Building models of population growth was a viable avenue to examining assumptions and seeing the element of surprise when counterintuitive patterns emerged. After examining the demographic distributions visualized by population pyramids, teachers raised questions about policies and cultural practices, as well as biological aspects that affect population growth. Serendipitously, the teachers reflected upon the impact of their own age cohort in terms of the future availability of social services. When the teachers examined historical practices of slavery, constructed fits to data of slave populations over time, and explored the spread of slave populations across the U.S. prior to the Civil War, they felt that they could encourage their students to discuss difficult issues of race, reproductive practices, and injustices.

We believe that engaging in-service teachers in problem posing that involves the examination and analysis of data with modeling, visualization, statistical analysis, and ethical discussion, empowers educators to construct brave spaces. By starting with quantitative reasoning about actual problems, where concrete data is available, teachers engaged in constructive discourse of culturally sensitive, even potentially taboo, subjects. These discussions were of enormous import to interpreting the impact of past injustices and making decisions about policies for looking into future possibilities.

We were quite intentional in introducing the notion of brave spaces in both teaching experiences described in this paper. We assert that the use of problem posing, data, modeling, statistical analysis, and visualization is an effective way to create brave spaces in classrooms. This strategy is in contradistinction to the type of "facilitation practices" advocated by Arao and Clemens $(2013,142)$ who argue that a carefully constructed set of ground rules for establishing and maintaining 
mutual respect was a necessary pre-condition to prepare teachers and students psychologically before approaching difficult issues in the classroom. Based on our experiences and observations of what teachers can do, we advocate that engaging teachers in the processes of data exploration and problem posing is an effective way to understand and use data in addressing topics of social justice. The particular quantitative examples we used serve as heuristics only, and we encourage teachers to select examples relevant to their contexts and goals in developing and supporting brave spaces.

\section{Acknowledgments}

We wish to especially thank Professor Linda Grisham, Mass Bay Community College, who stimulated many ideas for the authors to pursue. In addition, we are deeply grateful to readers and reviewers of multiple drafts of this manuscript: Professors Gabrielle Forman, English, and Jefferey Richardson, African American Studies, University of Delaware; Professor Paul McCreary, Mathematics, Evergreen State College; Professor Susan Jungck, Anthropology of Education, National Louis University; and Ann Bausum, author of many civil rights and social justice books. Funding from the Mathematics Science Partnership program facilitated by the Delaware Department of Education provided support for building and sustaining a community of educators who shared a passion for STEAM education and learning from one another.

\section{References}

Almond, Douglas, and Lena Edlund. 2007. "Trivers-Willard at Birth and One Year: Evidence from US Natality Data 1983-2001." Proceedings of the Royal Society of London B: Biological Sciences 274(1624): 2491-2496. https://doi.org/10.1098/rspb.2007.0524.

Arao, Brian and Kristi Clemens. 2013. "From Safe Spaces to Brave Spaces." In The Art of Effective Facilitation: Reflections from Social Justice Educators, edited by Lisa M. Landreman, 135-50. Sterling, VA: Stylus Publishing, LLC.

Behie, Alison M., and M. H. O'Donnell. 2018. "Higher Parental Perceptions of Wealth Associated with the Birth of More Sons in an Australian Population." Journal of Biosocial Science 50(4): 569-572. https://doi.org/10.1017/S0021932017000451.

Berlin, Ira. 2004. "American Slavery in History and Memory and the Search for Social Justice." The Journal of American History 90(4): 1251-1268. https://doi.org/10.2307/3660347.

Bloom, David E., David Canning, Günther Fink, and Jocelyn E. Finlay. 2009. "Fertility, Female Labor Force Participation, and the Demographic 
Dividend." Journal of Economic Growth 14(2): 79-101.

https://doi.org/10.1007/s10887-009-9039-9.

Brown, Stephen I., and Marion I. Walter. 2014. Problem Posing: Reflections and Applications. Hove, East Sussex, UK: Psychology Press. https://doi.org/10.4324/9781315785394.

Cai, Fang. 2010. "Demographic Transition, Demographic Dividend, and Lewis Turning Point in China." China Economic Journal 3(2): 107-119. https://doi.org/10.1080/17538963.2010.511899.

Cai, Jinfa, Stephen Hwang, Chunlian Jiang, and Steven Silber. 2015. "ProblemPosing Research in Mathematics Education: Some Answered and Unanswered Questions." In Mathematical Problem Posing: From Research to Effective Practice, edited by Florence Mihaela Singer, Nirida F. Ellerton and Jinfa Cai, 3-34. New York, NY: Springer. https://doi.org/10.1007/978-14614-6258-3_1.

Cameron, Elissa Z. 2004. "Facultative Adjustment of Mammalian Sex Ratios in Support of the Trivers-Willard Hypothesis: Evidence for a Mechanism." Proceedings of the Royal Society B: Biological Sciences 271(1549): 17231728. https://doi.org/10.1098/rspb.2004.2773.

Cavalli-Sforza, Luigi L. and W. F. Bodmer. 1971. The Genetics of Human Populations. San Francisco, CA: WH Freeman. http://bio.vtn2.com/biohome/harvey/lect/lectures.html?ccode=el\&mda=scrn $\&$ flnm $=$ nsln \&ttl=Population\%20change $\% 20$ and\%20natural\%20selection

Cook-Sather, Alison. 2016. "Creating Brave Spaces Within and Through StudentFaculty Pedagogical Partnerships." Teaching and Learning Together in Higher Education 1(18): 1.

https://repository.brynmawr.edu/tlthe/vol1/iss18/1.

Cunningham, Robert F. 2004. "Problem Posing: An Opportunity for Increasing Student Responsibility." Mathematics and Computer Education 38(1): 8389.

Dikötter, Frank. 2010. Mao's Great Famine: The History of China's Most Devastating Catastrophe, 1958-1962. New York, NY: Bloomsbury Publishing USA.

Dolan, Erin L. and James P. Collins. 2015. "We Must Teach More Effectively: Here Are Four Ways to Get Started." Molecular Biology of the Cell 26(12): 2151-2155. https://doi.org/10.1091/mbc.E13-11-0675.

Dupuis, Danielle N., Amanuel G. Medhanie, Michael R. Harwell, Brandon Lebeau, and D. Monson. 2012. "A Multi-Institutional Study of the Relationship between High School Mathematics Achievement and Performance in Introductory College Statistics." Statistics Education Research Journal 11(1): 4-gg20.

Ehrlich, Paul. 1968. The Population Bomb. New York, NY: Ballantine Books. 
Feng, Wang, Yong Cai and Baochang Gu. 2012. "Population, Policy and Politics: How Will History Judge China's One-Child Policy?" Population and Development Review 38 Population and Public Policy: Essays in Honor of Paul Demeny: 115-129

Frankenstein, Marilyn. 2013. "Reading the World with Math." In Rethinking School Mathematics: Teaching Social Justice by the Numbers, edited by Eric Gutstein and Bob Peterson, 30-39. Milwaukee, WI: Rethinking Schools, Ltd.

Freese, Jeremy, and Brian Powell. 1999. "Sociobiology, Status, and Parental Investment in Sons and Daughters: Testing the Trivers-Willard Hypothesis." American Journal of Sociology 104(6): 1704-1743. https://doi.org/10.1086/210221.

Freire, Paulo. 1968. Pedagogy of the Oppressed. New York, NY: Bloomsbury Publishing USA.

Grouws, Douglas A., James E. Tarr, Oscar Chávez, R. Sears, Victor M. Soria, and R. D. Taylan. 2013. "Curriculum and Implementation Effects on High School Students' Mathematics Learning from Curricula Representing SubjectSpecific and Integrated Content Organizations." Journal for Research in Mathematics Education, 44(2): 416-463. https://doi.org/10.5951/jresematheduc.44.2.0416.

Gutstein, Eric, Pauline Lipman, Patricia Hernandez, and Rebeca de los Reyes. 1997. "Culturally Relevant Mathematics Teaching in a Mexican American Context." Journal for Research in Mathematics Education 28(6): 709-737. https://doi.org/10.2307/749639.

Gutstein, Etic and Bob Peterson, eds. 2013. Rethinking School Mathematics: Teaching Social Justice by the Numbers, Second Edition. Milwaukee, WI: Rethinking Schools, Ltd.

Gutstein, Eric. 2018. "The Struggle Is Pedagogical: Learning to Teach Critical Mathematics." In The Philosophy of Mathematics Education Today, edited by Paul Ernest, 131-143. Cham, Switzerland: Springer. https://doi.org/10.1007/978-3-319-77760-3_8

Haraway, Donna. 1997.Modest_Witness@Second_Millenium.FemaleMan@ Meets OncoMouse ${ }^{T M}$. New York, NY: Routledge.

Harwell, Michael R., Amanuel G. Medhanie, Thomas R. Post, K. W. Norman, and Danielle N. Dupuis. 2012. "Preparation of Students Completing a CorePlus or Commercially Developed High School Mathematics Curriculum for Intense College Mathematics Coursework.” Journal of Experimental Education 80(1): 96-112. https://doi.org/10.1080/00220973.2011.567311.

Hirsch, Christian, James Fey, Eric Hart, Harold Schoen, and Ann Watkins. 2008. Core-Plus Mathematics: Contemporary Mathematics in Context, Course 1. New York, NY: McGraw Hill, Glencoe. 
Honey, Margaret, Greg Pearson, and Heidi Schweingruber, eds. 2014. STEM Integration in K-12 Education: Status, Prospects, and an Agenda for Research. Washington, DC: National Research Council.

hooks, bell. 2003. Teaching Community: A Pedagogy of Hope. New York, NY: Routledge.

Joyner, Michael. 2015. "Demography, Destiny \& Demographic Cliffs." (Posted on January $21^{\text {st }}$ ) http://www.drmichaeljoyner.com/2015/01/.

Jungck, John R. 1985. "A Problem Posing Approach to Biology Education." The American Biology Teacher 47(5): 264-266. https://doi.org/10.2307/4448046.

Jungck, John R., and Ranjan Roy. 2014. “3P'sU MMM in Finite Mathematics: A Union of the BioQUEST Curriculum Consortium's Problem Posing, Problem Solving, Peer Review/Publication Pedagogy with the Modified Moore Method." In Proceedings of the Symposium on BEER, 1(1)1-13.

Kanazawa, Satoshi. 2005. "Big and Tall Parents Have More Sons: Further Generalizations of the Trivers-Willard Hypothesis." Journal of Theoretical Biology 235(4): 583-590. https://doi.org/10.1016/j.jtbi.2005.02.010.

Kanazawa, Satoshi. 2007. "Beautiful Parents Have More Daughters: A Further Implication of the Generalized Trivers-Willard Hypothesis (gTWH)." Journal of Theoretical Biology 244(1): 133-140. https://doi.org/10.1016/j.jtbi.2006.07.017.

Kaňková, Š., J. Šulc, K. Nouzová, K. Fajfrlík, D. Frynta, and J. Flegr. 2007. "Women Infected with Parasite Toxoplasma Have More Sons." Naturwissenschaften 94(2): 122-127. https://doi.org/10.1007/s00114-0060166-2.

Kotlikoff, Laurence J., Kent Smetters, and Jan Walliser. 2007. "Mitigating America's Demographic Dilemma by Pre-Funding Social Security." Journal of monetary Economics 54(2): 247-266. https://doi.org/10.1016/j.jmoneco.2005.10.020.

Lee, Ronald, and Andrew Mason. 2006. "What is the Demographic Dividend?" Finance and Development 43(3): 16.

Liao, Yuen-Kuang, and Cheng-Ching Chang. 2016. "Effects of the Problem Posing Strategies of Students on Affective Learning Outcomes and Academic Achievement: A Meta-Analysis." Journal of Research in Education Sciences 61(3): 1-42.

Lin, See-Yan. 2015. The Global Economy in Turbulent Times. Singapore: John Wiley and Sons.

Mann, Charles C. 2018. The Wizard and The Prophet. Two Remarkable Scientists and Their Dueling Visions to Shape Tomorrow's World. New York, NY: Alfred A. Knopf, Inc.

Moses, Robert and C. E. Cobb. 2001. Radical Equations: Civil Rights from Mississippi to the Algebra Project. Boston: Beacon Press. 
National Council of Supervisors of Mathematics and TODOS. 2016. Mathematics Education through the Lens of Social Justice: Acknowledgement, Actions and Accountability. Jointly published by NCSM \& TODOS.

https://www.mathedleadership.org/docs/resources/positionpapers/NCSMPosi tionPaper16.pdf.

Newitz, Annalee. 2013. Scatter, Adapt and Remember: How Humans Will Survive a Mass Extinction. New York, NY: Doubleday.

Perez-Putnam, Miriam. 2016. "Belonging and Brave Space as Hope for Personal and Institutional Inclusion." Teaching and Learning Together in Higher Education 1(18): 2. https://repository.brynmawr.edu/tlthe/vol1/iss18/2

Peterson, Bob. 2013. "Write the Truth: Presidents and Slaves." In Rethinking School Mathematics: Teaching Social Justice by the Numbers, edited by Eric Gutstein and Bob Peterson, 226-237. Milwaukee, WI: Rethinking Schools, Ltd.

Post, Thomas R., Debbie Monson, Eric Anderson, and Michael Harwell. 2012. "Integrated Curricula and Preparation for College Mathematics." The Mathematics Teacher, 106(2): 138-143. https://doi.org/10.5951/mathteacher.106.2.0138.

Redmond, Melissa. 2010. "Safe Space Oddity: Revisiting Critical Pedagogy."Journal of Teaching in Social Work 30(1): 1-14. https://doi.org/10.1080/08841230903249729.

Reyes, Victoria, and Kirsten Adams. 2017. "Navigating a Difficult Journey:

Reflections on How a Student-Faculty Partnership Helped Address Racial Tensions in a Social Science Course." International Journal for Students as Partners 1(2). https://doi.org/10.15173/ijsap.v1i2.3262.

Rosling, Hans. 2012. Ted Talk: Religion and Babies. (Video and transcript). https://www.ted.com/talks/hans_rosling_religions_and_babies/tra nscript?language $=$ en.

Rosling, Hans, Ola Rosling, and Anna Rosling Ronnlund. 2018. Factfulness: Ten Reasons We're Wrong about the World - and Why Things are Better than You Think. London, England: Sceptre.

Scriver, Charles R. 2004. "The Human Genome Project Will Not Replace the Physician." Canadian Medical Association Journal 171(12): 1461-1464. https://doi.org/10.1503/cmaj.1041221.

Shetterly, Margot Lee. 2016. Hidden Figures. New York, NY: Harper Collins. Simon, Julian Lincoln. 1989. "On Aggregate Empirical Studies Relating Population Variables to Economic Development." Population and Development Review 15(2): 323-332. https://doi.org/10.2307/1973707.

Simon, R. 2016. The Touch of the Past: Remembrance, Learning and Ethics. New York, NY: Springer. 
Smils, Vaclav. 1999. "China's Great Famine: 40 Years Later.” British Medical Journal 319(7225): 1619-1621. https://doi.org/10.1136/bmj.319.7225.1619.

Tate, William. 2013. "Race, Retention and the Reform of School Mathematics." In Rethinking School Mathematics: Teaching Social Justice by the Numbers, edited by Eric Gutstein and Bob Peterson, 42-49. Milwaukee, WI: Rethinking Schools, Ltd.

Vanderklippe, Nathan. 2015. "The Ghost Children: In the Wake of China's OneChild Policy, a Generation is Lost." The Globe and Mail, March 13, 2015.

Van Harpen, Xianwei Y., and Norma C. Presmeg. 2013. "An Investigation of Relationships between Students' Mathematical Problem-Posing Abilities and Their Mathematical Content Knowledge." Educational Studies in Mathematics, 83(1), 117-132. https://doi.org/10.1007/s10649-012-9456-0.

Veller, Carl, David Haig, and Martin A. Nowak. 2016. "The Trivers-Willard Hypothesis: Sex Ratio or Investment?" Proceedings of the Royal Society B 283(1830): 2016.0126. https://doi.org/10.1098/rspb.2016.0126. 